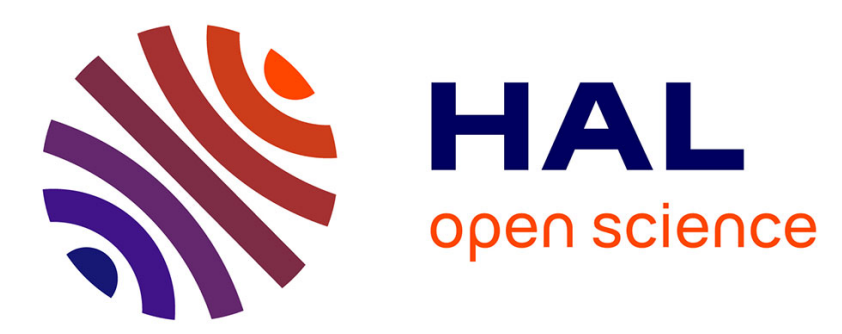

\title{
Effects of crystal preferred orientation on upper-mantle flow near plate boundaries: rheologic feedbacks and seismic anisotropy
}

\author{
D.K Blackman, D.E Boyce, O Castelnau, P.R Dawson, G Laske
}

\section{- To cite this version:}

D.K Blackman, D.E Boyce, O Castelnau, P.R Dawson, G Laske. Effects of crystal preferred orientation on upper-mantle flow near plate boundaries: rheologic feedbacks and seismic anisotropy. Geophysical Journal International, 2017, 210 (3), pp.1481-1493. 10.1093/gji/ggx251 hal-01676438

\section{HAL Id: hal-01676438 \\ https://hal.science/hal-01676438}

Submitted on 5 Jan 2018

HAL is a multi-disciplinary open access archive for the deposit and dissemination of scientific research documents, whether they are published or not. The documents may come from teaching and research institutions in France or abroad, or from public or private research centers.
L'archive ouverte pluridisciplinaire HAL, est destinée au dépôt et à la diffusion de documents scientifiques de niveau recherche, publiés ou non, émanant des établissements d'enseignement et de recherche français ou étrangers, des laboratoires publics ou privés. 


\title{
Effects of crystal preferred orientation on upper-mantle flow near plate boundaries: rheologic feedbacks and seismic anisotropy
}

\author{
D.K. Blackman, ${ }^{1}$ D.E. Boyce, ${ }^{2}$ O. Castelnau, ${ }^{3}$ P.R. Dawson ${ }^{2}$ and G. Laske ${ }^{1}$ \\ ${ }^{1}$ Scripps Institution of Oceanography, UCSD, La Jolla, CA 92093,USA.E-mail: dblackman@ucsd.edu \\ ${ }^{2}$ Cornell University, Ithaca, NY 14850, USA \\ ${ }^{3}$ PIMM-UMR8006, CNRS, ENSAM, CNAM, F-75013 Paris, France
}

\begin{abstract}
S UMMAR Y
Insight into upper-mantle processes can be gained by linking flow-induced mineral alignment to regional deformation and seismic anisotropy patterns. Through a series of linked micro-macro scale numerical experiments, we explore the rheologic effects of crystal preferred orientation (CPO) and evaluate the magnitude of possible impacts on the pattern of flow and associated seismic signals for mantle that includes a cooling, thickening young oceanic lithosphere. The $\mathrm{CPO}$ and associated anisotropic rheology, computed by a micromechanical polycrystal model, are coupled with a large scale flow model (Eulerian Finite Element method) via a local viscosity tensor field, which quantifies the stress:strain rate response of a textured polycrystal. CPO is computed along streamlines throughout the model space and the corresponding viscosity tensor field at each element defines the local properties for the next iteration of the flow field. Stable flow and CPO distributions were obtained after several iterations for the two dislocation glide cases tested: linear and nonlinear stress:strain rate polycrystal behaviour. The textured olivine polycrystals are found to have anisotropic viscosity tensors in a significant portion of the model space. This directional dependence in strength impacts the pattern of upper-mantle flow. For background asthenosphere viscosity of $\sim 10^{20} \mathrm{~Pa}$ s and a rigid lithosphere, the modification of the corner flow pattern is not drastic but the change could have geologic implications. Feedback in the development of CPO occurs, particularly in the region immediately below the base of the lithosphere. Stronger fabric is predicted below the flanks of a spreading centre for fully coupled, power-law polycrystals than was determined using prior linear, intermediate coupling polycrystal models. The predicted SKS splitting is modestly different $(\sim 0.5 \mathrm{~s})$ between the intermediate and fully coupled cases for oceanic plates less than 20 Myr old. The magnitude of azimuthal anisotropy for surface waves, on the other hand, is predicted to be twice as large for fully coupled power-law flow/polycrystals than for linear, intermediate coupled flow/polycrystal models.
\end{abstract}

Key words: Mantle processes; Seismic anisotropy; Rheology: mantle.

\section{KEY POINTS}

- Flow-induced crystal preferred orientation results in anisotropic upper-mantle viscosity

- Viscosity tensor based on crystal preferred orientation is integrated with flow calculation

- CPO-flow feedback occurs, associated surface seismic signal increases with oceanic plate age

\section{GJI SECTION}

- Geodynamics and tectonics

- Mineral physics, rheology, heat flow and volcanology

- Seismology

\section{INTRODUCTION}

The dominant minerals in the upper mantle have anisotropic single crystal properties. The seismic anisotropy of mantle peridotite arising from deformation-induced crystal alignment is well known (Birch 1960; Mainprice et al. 2000) but the rheologic anisotropy of these olivine $(\sim 70$ per cent):enstatite $(\sim 30$ per cent) polycrystals is less well known (Castelnau et al. 2009; Hansen et al. 2012). This study explores the rheologic anisotropy that is associated with texturing of mantle rock during viscous mantle flow. Texture develops due to deformation of individual mineral grains at stress levels that typify regions with upper-mantle flow gradient (Carter 1976; Nicolas \& Poirer 1976; Karato 2008). Dislocation glide along favourably oriented mineral slip systems results in alignment of mineral lattices in a direction controlled by the evolving stress field 
that a polycrystal experiences within the flow field. Significant alignment of mineral grains within a polycrystal is referred to as crystal preferred orientation (CPO).

Knowledge about convection in the upper mantle can inform many aspects of deep Earth structure and processes but it is not possible to directly observe the flow field. Interpretations of observed seismic anisotropy provide one means to infer mantle flow patterns (McKenzie 1979; Ribe 1989; Long \& Becker 2010) and what they might imply about, for example, the nature and extent of coupling across the lithosphere-asthenosphere boundary (Nicolas \& Violette 1982; Tommasi et al. 2000; Olugboji et al. 2016), or the interactions between partial melting and flow in the vicinity of plumes or plate boundaries (Holtzmann \& Kendall 2010). Experimental results (Karato 2008; Boneh et al. 2015; Hansen et al. 2016) and natural sample measurements (Ben Ismail \& Mainprice 1998) of olivine deformation provide constraints on numerical simulations of mantle polycrystal behaviour under various applied stresses (Wenk et al. 1991; Tommasi 1998; Dawson \& Wenk 2000; Kaminski \& Ribe 2002; Castelnau et al. 2008; Li et al. 2014; Goulding et al. 2015). Here we build on prior numerical developments and benchmarking. We apply the method that is currently best suited to address polycrystal rheology in an evolving stress field - the viscoplastic self-consistent second-order (VPSC-SO) scheme, which has been shown to predict olivine orientation distributions similar to natural and experimentally obtained fabrics (Castelnau et al. 2008) and to match full-field simulations of polycrystal behaviour under deformation (Lebensohn et al. 2004).

A key motivation of this study is to consider general deformation and corresponding rheologic changes due to CPO for an evolving upper-mantle stress field. Prior works on the effect of anisotropic mantle rheology on flow adopt a single weak and perpendicular strong direction, assigned relative to the flow (Honda 1986; Christensen 1987; Mülhaus et al. 2004; Lev \& Hager 2008). The impacts of such rheology were found to be geologically relevant. Such a transverse isotropy approach can be useful away from plate boundaries, where hexagonal elastic symmetry provides a fairly robust approximation to observed global azimuthal anisotropy patterns. However, the hexagonal assumption has been shown to not match splitting observations near rifts and plate margins (Becker et al. 2006a). Tracking the continuously evolving CPO is necessary in order to assess how texture-related viscosity changes may develop in regions of complex flow.

\section{NUMERICAL MODELLING}

An iterative procedure is used to solve for upper-mantle flow within a few hundred $\mathrm{km}$ of an oceanic spreading centre and the associated CPO (Fig. 1). Viscosities throughout the model space are updated for every iteration. The initial flow solution assumes isotropic (scalar) viscosity, with a value of $10^{20} \mathrm{~Pa}$ s in the asthenosphere and $10^{23} \mathrm{~Pa}$ in the lithosphere. The base of the lithosphere is the $1000^{\circ} \mathrm{C}$ isotherm. Subsequent iterations use a viscosity tensor determined for a polycrystal that has developed CPO along a flow line from the base of the model to the point under consideration. A viscosity tensor is determined for each element in the model. Flow, CPO, and viscosity iteration proceeds until the maximum change in local flow velocity is less than 1 per cent of the specified plate spreading rate and CPO changes throughout the model are negligible. The seismic anisotropy associated with this stable distribution of CPO is then computed throughout the model space and surface observables are predicted. Details of the method are described in Sections 2.1 and 2.2 .
Our main goal is to determine whether feedback between CPO, upper-mantle flow pattern, and seismic anisotropy may occur at a scale that is significant. This investigation is not intended to produce precise predictions of the distribution of seismic anisotropy near a spreading centre. Rather, we aim to understand the level of bias that may be associated with the majority of flow/CPO simulations in the recent geophysical literature, where rheologic impacts of texture have been ignored (Chastel et al. 1993; Tommasi 1998; Blackman et al. 2002; Kaminski \& Ribe 2002; Becker et al. 2006b).

We emphasize plastic deformation that develops through dislocation glide. It is clear that other deformation mechanisms can operate in regions of the upper mantle, for example, dislocation climb (Goetze \& Kohlstedt 1973) and grain boundary sliding (Hansen et al. 2012). Dynamic recrystallization could also come into play (Zhang et al. 2000; Karato 2008). The strength and types of CPO distributions that are produced when these other mechanisms (also) operate tend to basically follow alignment directions for polycrystals where dislocation glide is dominant (e.g. Lebensohn et al. 2010) although fabric strength may be overestimated (Raterron et al. 2014) and high strain or hydration can alter recrystallized grain orientation in some cases (Zhang et al. 2000). Differences in rates of CPO evolution and precise orientations for these other mechanisms have been reported, as discussed in Section 2.1. We choose an upper value for overall viscosity within an upwelling zone near a spreading centre $\left(10^{20} \mathrm{~Pa} \mathrm{~s}\right)$. The resulting flow field is a broad, passive response to plate motion, rather than containing a subaxial zone with very high flow gradients and strong CPO associated with buoyancy enhanced upwelling in the partial melting zone, which results for asthenosphere viscosity of $5 \times 10^{18-19}$ Pa s (Jha et al. 1994; Blackman et al. 1996; Blackman \& Kendall 2002). This broad flow is useful in itself (an endmember flow model) and it has just a single change in flow direction (the 'corner'), so potential, second-order biases associated with the simplified deformation mode that we adopt should be less prevalent.

The computational cost of fully coupled flow/CPO/viscosity calculations is significant so we limit our model space to a region $200 \mathrm{~km}$ wide. This model space includes the upwelling zone beneath a slow $\left(10 \mathrm{~km} \mathrm{Myr}^{-1}\right)$ spreading centre, the flow 'corner', and the onset of plate-driven shearing, which dominates evolution of the off-axis CPO. The base of the model is set at a depth $150 \mathrm{~km}$, restricting the region to conditions that Raterron et al. (2014) indicate would have nearly constant critical resolved shear stress threshold for olivine slip systems; pressure $(P)$ and temperature $(T)$ influences are modest for this region underlying oceanic crust 0-20 Myr old. Hadjazian et al. (2017) combine deformation and seismic anisotropy modelling to explore changes as a function of ocean lithosphere age. While additional tests of their parameterizations for deformation by dislocation and diffusion are warranted, their findings suggest that the former mechanism may dominate the latter in the asthenosphere throughout our model space. We assume that CPO is random as polycrystals enter the base of the model. Inclusion of $P / T$ effects on slip system activity and/or the impacts of pre-existing texture (Raterron et al. 2014; Boneh et al. 2015) should be addressed in the future with larger models, but first it is important to establish whether the scale of feedback even warrants additional effort.

\subsection{Flow, CPO, and viscosity finite element calculations}

Mantle flow is computed using a parallel finite element (FEM) code, Isaiah, developed at Cornell University. Isaiah solves a coupled system of equations for velocity, temperature and model state variables 


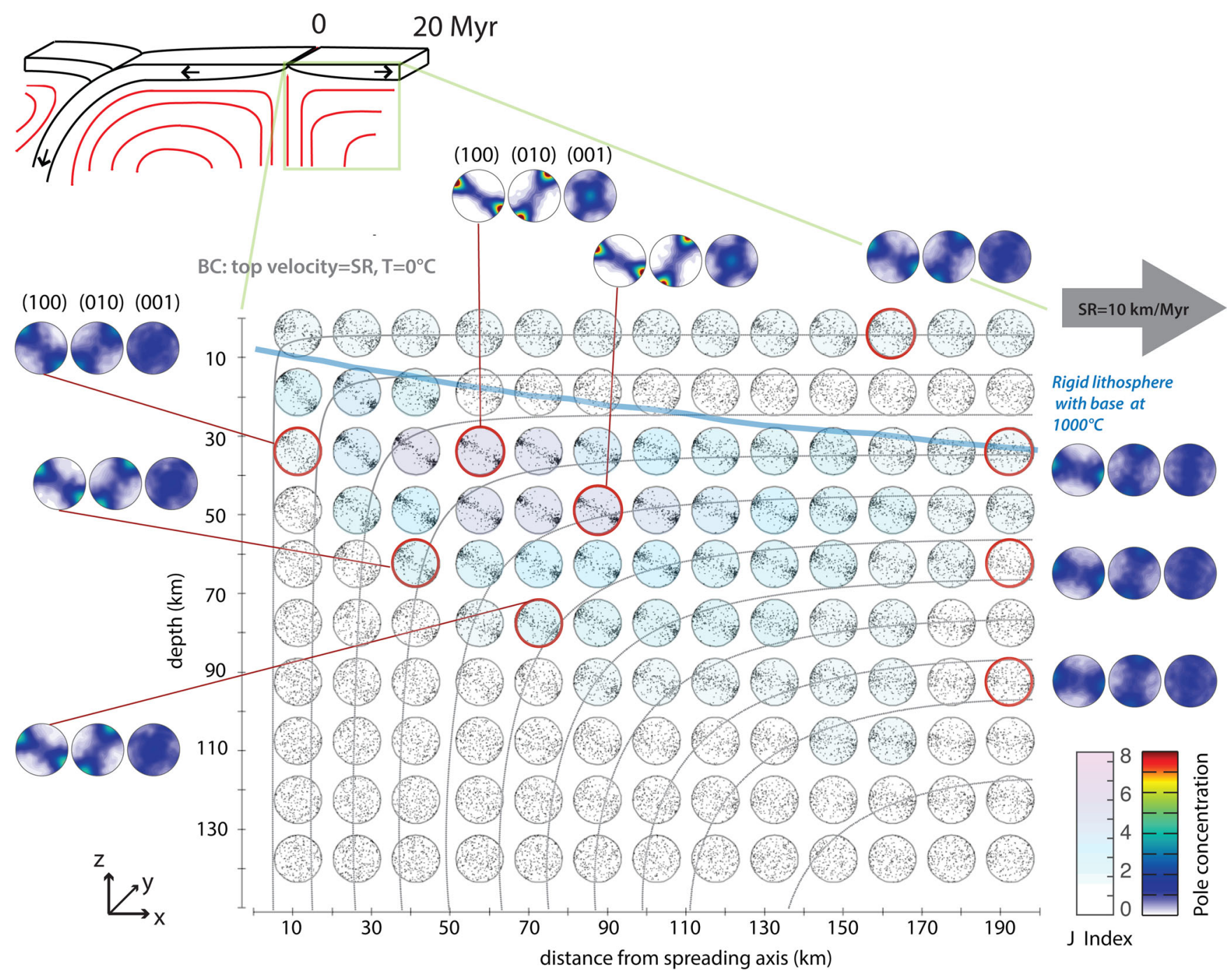

$\mathrm{BCs}$ : horizontal gradients at axis $=0$; model base- random CPO, $\mathrm{T}=1300^{\circ} \mathrm{C}$, stress free

BC: flow horizontal at side

Figure 1. Intermediate coupling (first iteration) reference case showing flow lines (grey) and olivine CPO. 1000-grain $a$-axis pole figures (equal area, lower hemisphere) are shown throughout the model space. Sketch in upper left shows portion of ocean spreading centre system that is modelled (green square). Boundary conditions (BC) for the flow model are noted in grey text. Viscosity is scaled by $10^{3}$ for lithospheric temperatures $\left(T<1000{ }^{\circ} \mathrm{C}\right)$, polycrystal is specified to have linear stress:strain rate behaviour. $J$ index for each pole figure is indicated by colour shading. Contoured pole figures with constant colour scale (red, high concentration of poles; blue, low concentration) are shown for selected locations (red circles), and each of the three olivine axes is shown. Slow spreading rate (SR) is specified so model represents plate ages 0-20 Myr.

in three dimensions. It uses an Eulerian framework and treats the problem as a steady flow. For this work, we implemented a viscoplastic flow model using an anisotropic viscosity tensor field; no state variables were used, non-Newtonian behaviour is introduced via the viscosity tensor. Isaiah was developed for modelling the nonlinear viscoplastic flow of polycrystalline metals during large strain deformation processes. It has been applied to deformation processes, such as rolling (Lee et al. 1990) and solid state joining processes, such as friction stir welding (Cho et al. 2007; Cho \& Dawson 2008; Boyce \& Dawson 2014a,b). In our case, full implementation would set the CPO-based viscosity as the state variable for each element; the results reported here represent partial implementation for the purpose of determining the scale of flow/CPO feedbacks. Rather than storing element CPO, we compute CPO evolution for full streamlines (from the model base to every element) at each iteration. Finer mesh discretization (i.e. smaller nodal point spacing of $2.5 \mathrm{~km}$ ) is used in a zone underlying the spreading axis and also in the top portion of the model where gradients near the thickening lithosphere are high. Coarser mesh discretization (i.e. greater nodal point spacing of $5 \times 5 \mathrm{~km})$ is used at depths $(z)$ greater than $50 \mathrm{~km}$ and off-axis distances $(x)$ greater than $50 \mathrm{~km}$. Since we focus on variation in the direction of spreading (cross-axis) for this study, boundary conditions (Fig. 1 and Supporting Information) drive a 2-D flow and out-of-plane variation in the velocity field is negligible. The maximum difference of the converged velocity field in the $y$ direction occurred at the spreading axis and in narrow radial bands emanating up to $50 \mathrm{~km}$ away from it. The magnitude of the along-strike difference in the $x$ and $z$ velocity components in this region dropped from 0.05 per cent to less than 0.01 per cent of the specified spreading rate.

The VPSC-SO method used for calculating CPO and effective viscosity of a polycrystal deals with nonlinear viscoplastic 
Table 1. Olivine slip systems for each grain in the polycrystal and the critical resolved shear stress (CRSS) required for slip to be activated. The 1:10 ratio for slip along the $a$ versus $c$ axis results in anisotropy for a linear polycrystal that is consistent with observed values. For simplicity, that ratio was retained in our power-law polycrystal runs. This choice has limited effect on CPO development (Supporting Information Fig. S3).

\begin{tabular}{ll}
\hline Slip system & Reference stress \\
\hline$(010)[100]$ & $5.5 \times 10^{-4}(\mathrm{MPa})$ \\
$(001)[100]$ & $5.5 \times 10^{-4}$ \\
$(010)[001]$ & $5.5 \times 10^{-3}$ \\
$\{101\}\langle\overline{101}\rangle$ & $5.5 \times 10^{-2}$ \\
\hline
\end{tabular}

behaviour by constructing a linear comparison polycrystal (LCP). The LCP provides a reliable approximation of the effective behaviour of composite materials that may have power-law stress:strain rate response (Ponte Castañeda 2002; Lebensohn et al. 2007) such as determined for olivine (e.g. Bai et al. 1991; Hirth $\&$ Kohlstedt 2003). There is general agreement in the direction of preferred orientation predicted by the dislocation-only VPSC-SO method and that determined by laboratory shear experiments on olivine, but rates of change can be slower and peak concentration of axes can be off by $5-20^{\circ}$ during simple shear (Signorelli \& Tomassi 2015; Hansen et al. 2016). Subgrain rotation during recrystallization and grain boundary sliding might be key explanations for the differences. This means that our results will indicate the basic nature of CPO variability within the model space and the potential impact on flow pattern, but a more complete set of deformation mechanisms will need to be modelled to obtain detailed results. Since the VPSC tends to predict slower CPO rotation under shear than when subgrain rotation is included (Signorelli \& Tommasi 2015), our determinations can provide a conservative estimate of the CPO-flow feedbacks.

The code developed by the CNRS, Paris group was designed to calculate CPO and effective viscosity for polycrystals as they experience evolving stress while transiting along a streamline through a flow field. Olivine slip system parameters were set (Table 1) for 1000 -grain polycrystals. Enstatite was not considered since its inclusion does not significantly alter the predicted orientation of olivine alignment (Blackman et al. 2002), thus strength directionality of the polycrystal is reliably determined. The adopted low activity, fourth (hard) system does not significantly affect CPO development (Castelnau et al. 2008, 2009; Detrez et al. 2015) but is necessary for our dislocation-glide (only) model since the three independent olivine slip systems alone are insufficient to accommodate general deformation. Mantle flow streamlines ending at each element, and the associated velocity gradients at increments of 2.5 per cent strain along the path, were calculated with Isaiah. These were linked to a modularized version of the CNRS code. CPO is calculated at each streamline increment and used as the starting distribution for further evolution based on the local stress field at the next position along the streamline. Once temperature drops below $1000^{\circ} \mathrm{C}$, texturing is stopped and the 'frozen in' CPO is allocated to the element at the streamline endpoint. The mechanical response of the polycrystal, once final CPO is achieved, is calculated and this defines the effective viscosity tensor. At this stage, $\mathrm{CPO}$ is the only factor affecting viscosity of the polycrystal. The $6 \times 6$ viscosity tensors values are scaled by $10^{3}$ if the element resides in the lithosphere, and the tensors are then employed in the next flow iteration with Isaiah to specify local stress:strain rate behaviour.

The quantitative criteria for assessing convergence emphasized velocity field stability. A maximum difference of less than 1 per cent of the spreading rate was required and this maximum characterized less than 5 per cent of the model space. Most velocity field values were nearly an order of magnitude less different between iterations when convergence was determined. Gradients in velocity control CPO evolution and thus viscosity, so stability in the former go hand in hand with stability in the latter. The distribution and intensity of CPO was qualitatively determined to have stabilized based on pole figure comparison between iterations. Finally, viscosity tensor components were also compared between iterations and convergence was affirmed when changes between runs were not significant for any component.

Two sets of calculations were performed: the first set assumed linear stress:strain rate behaviour for the polycrystal. This allowed a computationally efficient test of the iteration procedure and provides a first look at potential feedbacks for olivine flow/CPO using the same parameter settings as in Castelnau et al. (2009). For portions of the model where texture is nearly random, this $n=1$ case corresponds to Newtonian flow with isotropic viscosity, but the overall flow pattern reflects significant spatial variation in viscosity, a majority of which is anisotropic. In order to track the flow, CPO, and viscosity through iterations, orientation distributions were saved for elements spaced every $15 \mathrm{~km}$ throughout the model along with representative streamlines and compared to prior iteration results. Full model viscosity tensor components were also assessed between iterations. Fig. 1 presents results for the case denoted 'intermediate coupling' for which CPO are calculated for the flow pattern predicted when using an isotropic viscosity. This corresponds to the first iteration of the fully coupled model. The second set of calculations is performed similarly, but accounting for nonlinear viscosities where a stress exponent $n=2$ or 3 is adopted for the polycrystal. For these power-law polycrystal cases, the $\mathrm{CPO}$ calculation requires slower adoption of evolution updates. The solution for each streamline position is approached stepwise, with CPO update phased in through adoption of a polycrystal stress that is a weighted average of the latest (current) and prior determinations. This weighting factor, F, of the current stress was set at 0.75 for the majority of the $n=2$ streamlines. A few streamlines with high velocity gradients required the current stress to have a weighting of 0.33 to slow the adoption of the updated stress in order to achieve convergence. Weights of $0.25-0.33$ were consistently required for $n=3$ runs. Computation time increases significantly as $F$ is decreased, with the $n=2$ case requiring more than an order of magnitude longer for each of streamlines than for the linear case $(F=1)$.

\subsection{Seismic anisotropy calculations}

Body wave anisotropy was computed based on CPO at elements spaced $15 \mathrm{~km}$ apart throughout the model using prior procedures (e.g. Blackman et al. 2002). Effective elastic constants were determined using Voigt-Reuss-Hill average of single-crystal properties (Anderson \& Isaak 1995), projected onto the global reference frame, over all 1000 grains in the local polycrystal. Given the limited depth extent of our model, including $P / T$ dependence of elastic constants would not alter results (Blackman \& Kendall 2002) so we use values for standard temperature and pressure. Local $P$-wave anisotropy and shear wave splitting were computed on the $15 \mathrm{~km}$ subgrid, a minimum curvature surface was fit to these data using GMT (Wessel 


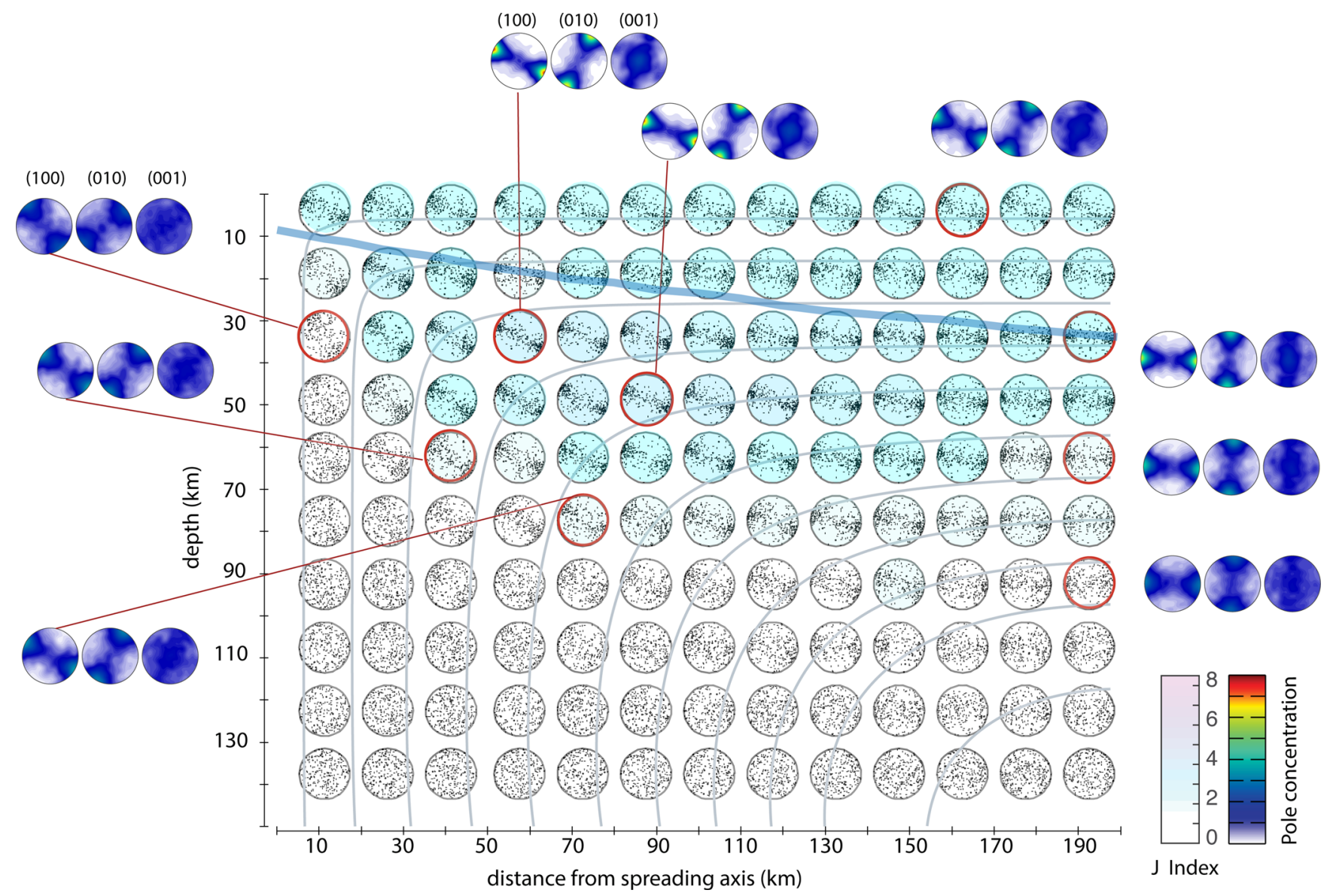

Figure 2. Fully coupled, linear polycrystal flow field and CPO, stabilized at iteration 15. Format and colour scales are the same as in Fig. 1, with $a$-axis pole figures shown throughout model, colour shaded by $J$ index. At select locations, pole concentrations for all three olivine axes are shown.

\& Smith 1998), and then values were resampled at $10 \mathrm{~km}$ spacing. SKS splitting accrued by seismic waves traveling vertically through the model was approximated by summing local split times for each column of the subgrid. Ray bending was neglected, but would be modest for these models (Blackman \& Kendall 1997).

Surface wave azimuthal anisotropy was determined for the $20 \mathrm{Myr}$ portion of the model, using elastic constants computed from the depth distribution of $\mathrm{CPO}$ at the right edge of the model. A derivative of the seismic normal mode code MINOS (see Woodhouse 1988 for theoretical background) was used, which incorporates weak general seismic anisotropy (Tanimoto 1986), on the order of a few per cent, that can be formulated by perturbation theory. The spherical 1-D model 1066A (Gilbert \& Dziewonski 1975) was sampled and interpolated at $5 \mathrm{~km}$ depth intervals to compute vertical normal mode eigenfunctions and sensitivity kernels. As with predictions for body waves, here we only predict dispersion caused by structure as defined by the computed elastic parameters. We do not attempt to model wave propagation effects. To this end, lateral tomographic resolvability will depend on seismic data density, that is, ray path coverage, and is not discussed further.

\section{RESULTS}

\subsection{Linear polycrystal}

The fully coupled, linear polycrystal case converged in 15 iterations, with flow field and CPO stable throughout the model space (Fig. 2).
Overall flow and general olivine alignment are predicted to differ modestly from the intermediate coupling result (Fig. 1). Material that starts within $50 \mathrm{~km}$ of the spreading axis rises to somewhat shallow depth (a few km further), but at a slightly reduced rate (up to 10 per cent of the SR slower). Streamline inflection at the corner in the flow field is not quite as sharp, and CPO is correspondingly weaker in that region. Similar to the intermediate coupling result, texture strength decreases somewhat as plate shearing becomes dominant off-axis $(x>125-150 \mathrm{~km})$, but for the fully coupled case, the sublithosphere CPO persists, rather than diffusing due to the change in shear direction, and becomes aligned more closely with the spreading direction. The $J$ index provides a useful quantification of fabric strength (Ben Ismail \& Mainprice 1998) and values of 2-3 are common in the upper half of the fully coupled model, where texture has evolved from the initial random distribution; just a portion of the corner region $(x \sim 60-120 \mathrm{~km})$ has higher $J$ index of $4-5$. The latter contrasts with the intermediate coupling result where $J$ index values of $6-8$ occur in this part of the flow corner and $c$-axes are more concentrated in the out-of-plane $(y)$ direction. By $20 \mathrm{Myr}, b$-axis concentrations in the region beneath the lithosphere have increased, with maxima in the vertical direction.

The extent to which the effective viscosity of the textured polycrystals deviates from isotropic varies with position in the model. For intermediate coupling, individual tensor components deviate most strongly near the flow corner and below the young lithosphere (Fig. 3a). For the fully coupled polycrystal, the lower lithosphere and the region extending below its base have viscosity components 
(a) $n=1$, it1

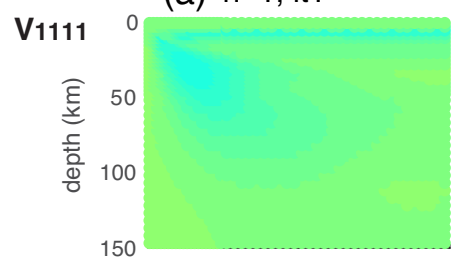

$V_{1133}$
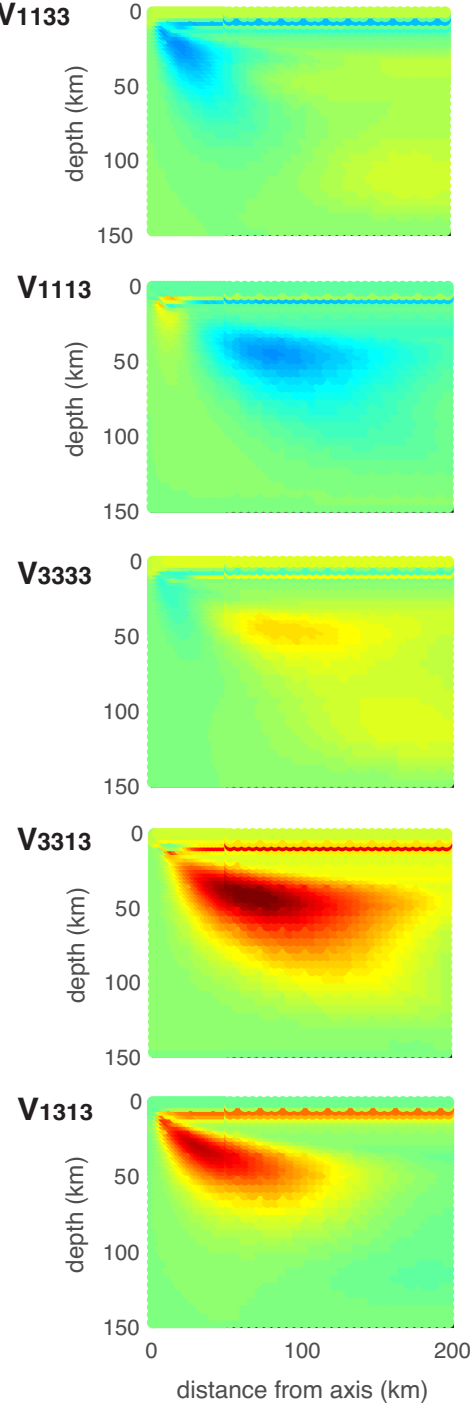

(b) $n=1$, it15
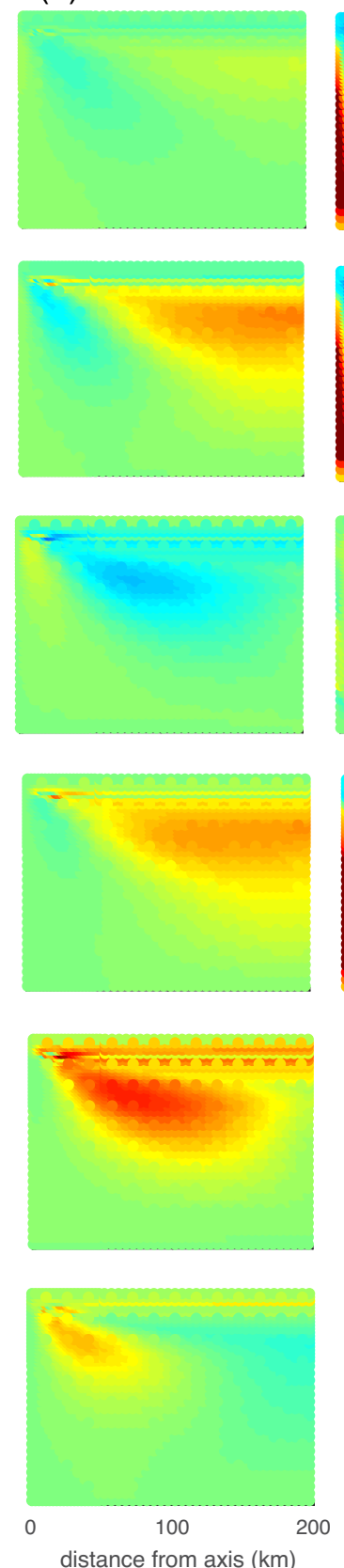

(c) n=2, it1
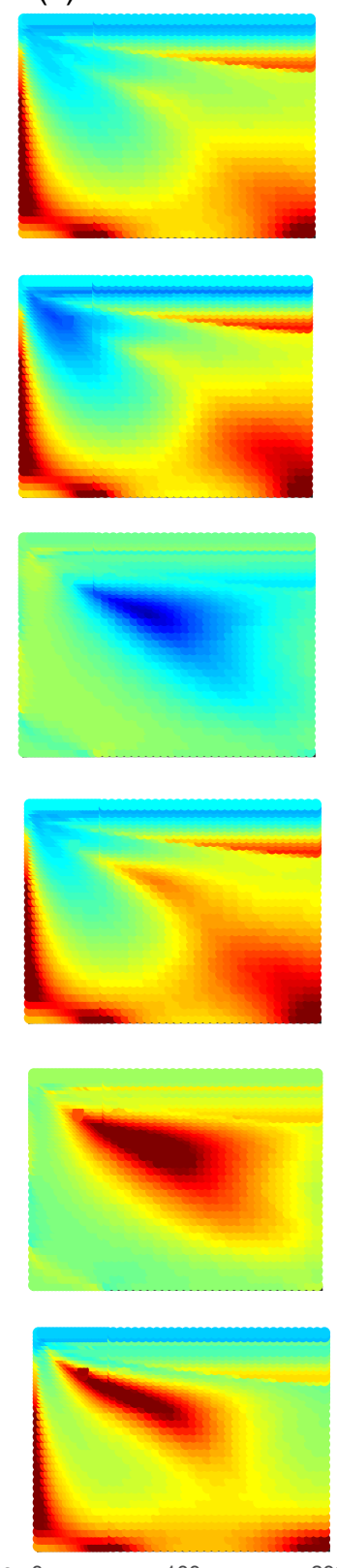

100

distance from axis $(\mathrm{km})$ (d) $n=2$, it4
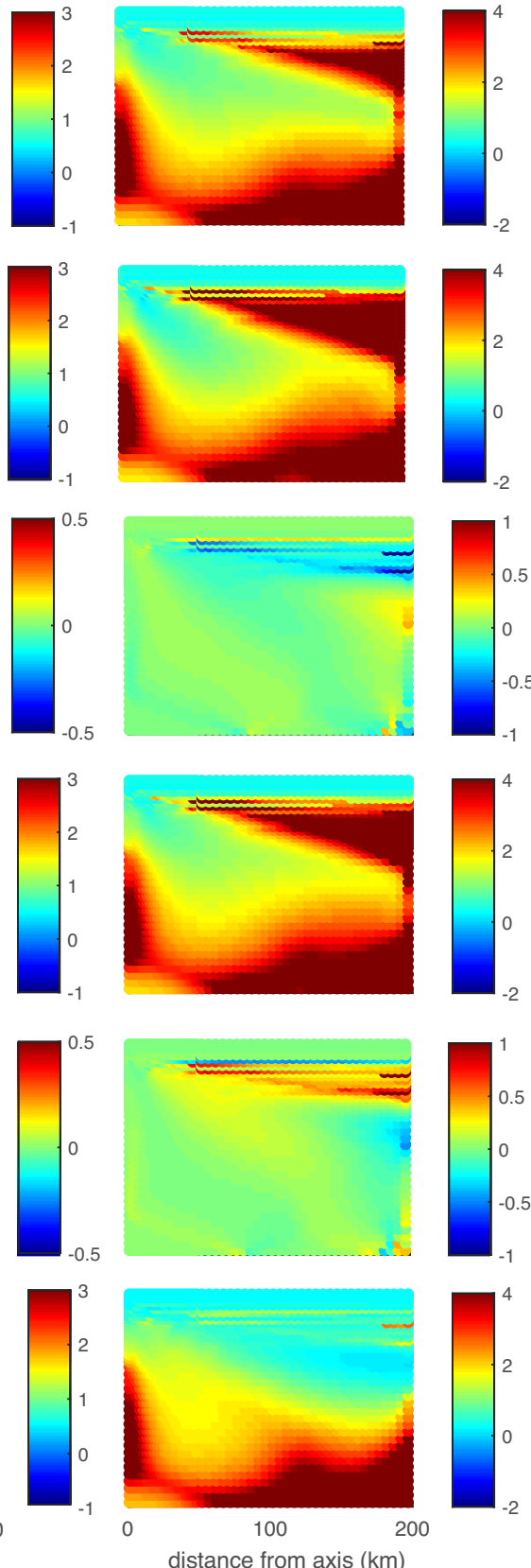

Figure 3. Normalized viscosity tensor components for different models of flow/CPO. The six independent components of the $6 \times 6$ tensor are plotted for each model. Deviation from isotropic value (green) is highlighted by dividing each component by that isotropic value: (a) intermediate coupling, linear polycrystal case; (b) fully coupled, linear polycrystal case; (c) fully coupled, power-law polycrystal case with stress exponent $n=2$, first iteration; (d) fully coupled, power-law polycrystal case with stress exponent $n=2$, fourth iteration. Colour scale for (a)-(c) is shown to right of (c). Colour scale for (d) is shown at far right.

that deviate more strongly from an isotropic tensor than the flow corner (Fig. 3b).

The seismic signature of the fully coupled, linear polycrystal model would be difficult to distinguish from that of the intermediate coupling case using surface (seafloor) measurements. While there is clearly some feedback between CPO and flow, the impact on seismic anisotropy is modest for this case (Figs $4 a$ and $b$ ). There are differences in local elastic properties, particularly for variably incident $\mathrm{S}$ waves, but the total $P$-wave delay or SKS splitting times are only slightly altered within this young oceanic plate region.
Fast directions (the fast $S$-wave will be polarized in the direction of the fast $P$-wave direction for CPO such as we predict in this model), become parallel to the direction of plate motion shortly after $10 \operatorname{Myr}(x \sim 100 \mathrm{~km})$ for the fully coupled case, whereas they retain alignment developed in the flow corner throughout much of the modelled region in the intermediate coupling case. Splitting of $S$-waves within the $25-50 \mathrm{~km}$ depth interval is greater at ages older than $10 \mathrm{Myr}$ in the fully coupled case. This effect will increase further off-axis as plate-drive shearing proceeds (and the plate cools and thickens), but at the $20 \mathrm{Myr}$ age, it would not be possible 
(a)
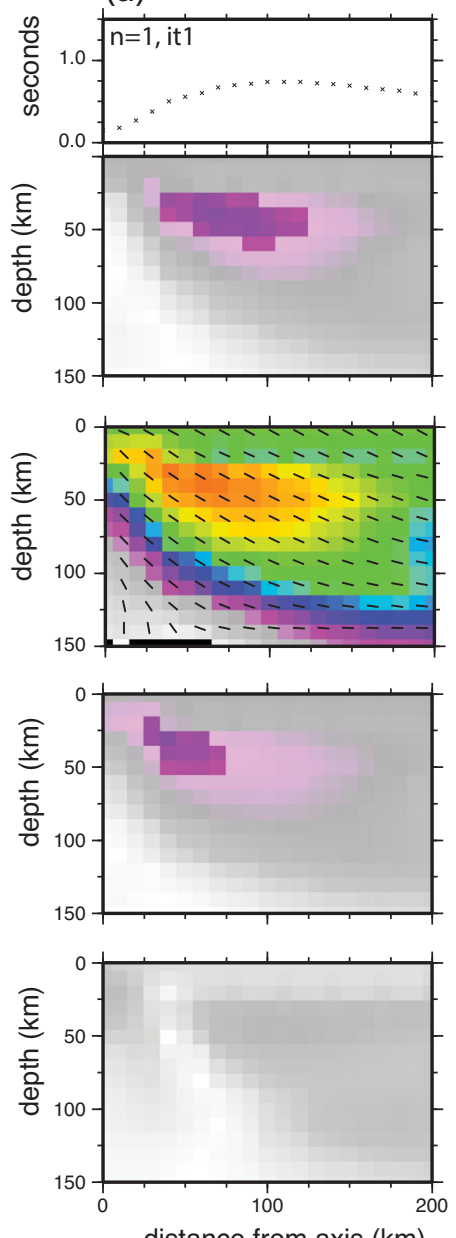

distance from axis $(\mathrm{km})$ (b)
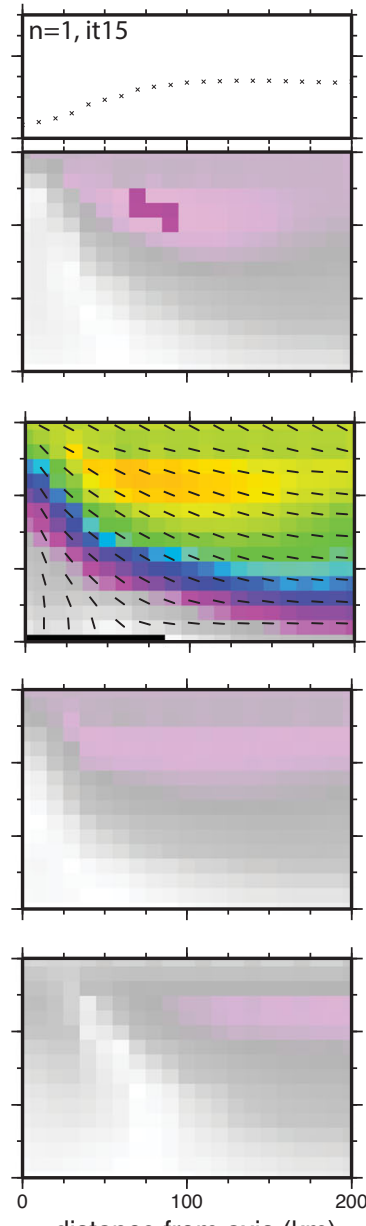

(c)

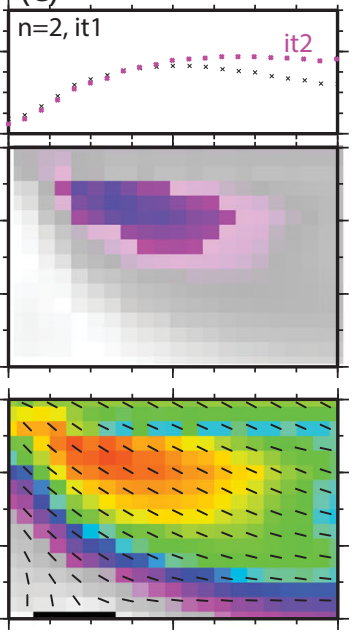

(e)
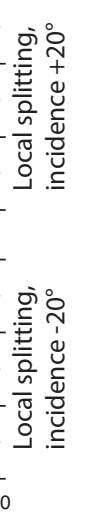

distance from axis $(\mathrm{km})$

(d)

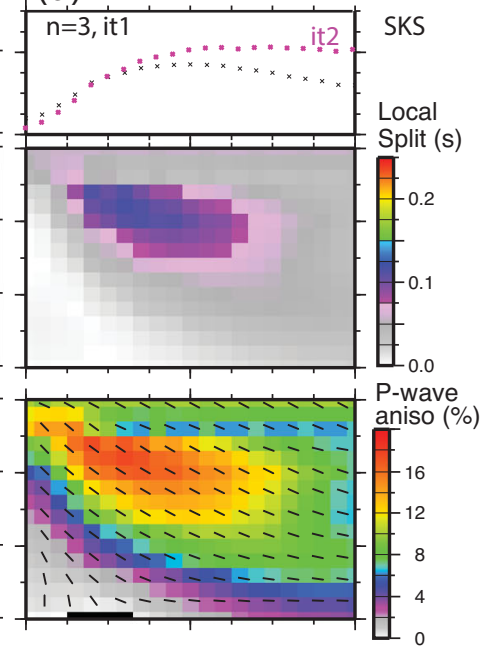

$(f)$

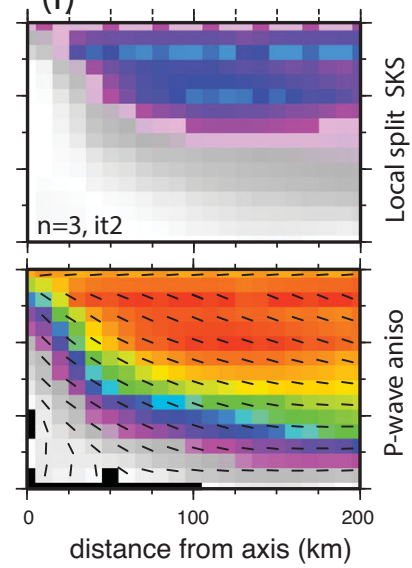

Figure 4. Seismic anisotropy associated with different models of linked flow, CPO and polycrystal stress:strain rate assumption. Top panels (a-d) show SKS splitting accrued by waves transiting at vertical incidence through the local shear wave structure, with black $\times$ 's corresponding to immediately underlying panels. Pink $\times$ 's show SKS splitting accrued for local structure shown in top panels of (e) and (f). P-wave anisotropy in the model is shown (below local SKS panels) by separate colour scale with overlain, constant-length vectors showing the direction of fastest propagation. The lower two panels in (a) and (b) show local $S$-wave splitting for $\pm 20^{\circ}$ incidence. (a) Intermediate coupling (iteration 1) case for linear polycrystal. (b) Fully coupled case, iteration 15 for linear polycrystal. (c) Intermediate coupling case for power-law polycrystal with stress exponent $n=2$. (c) Intermediate coupling case for power-law polycrystal with $n=3$. (e) Coupled case at second iteration, $n=2$. (f) Coupled case at second iteration, $n=3$.

to resolve differences in the surface measurements between the intermediate and fully coupled cases.

\subsection{Power-law polycrystal}

Olivine single crystal creep is expected to occur at rates proportional to the applied stress raised to a power of $\sim 3.5$ (Bai et al. 1991), although behaviour probably depends on several factors as mantle depth increases (Raterron et al. 2009). Polycrystal behaviour is more complex due to grain-grain interactions (Lebensohn et al. 2016) (and the presence of other minerals) so the appropriate stress exponent is uncertain. Since it is clear that peridotite deforms with some degree of nonlinearity (Carter 1976; Nicolas \& Christensen 1987), incorporating this effect allows us to move beyond the limited exploration possible with the linear polycrystal case. For this assessment, we considered cases with stress exponent $(n)$ of 2 and 3.

For intermediate coupling, flow and CPO are generally similar for the power-law cases $(n=2$ and 3$)$ and the linear $(n=1)$ case, though fabric is somewhat more intense in the flow corner region as indicated by $J$ index values that are about 1 point greater there. The difference in intermediate coupling results for the $n=2$ and $n=3$ power-law polycrystal cases is minor. Predicted seismic anisotropy (Figs $4 \mathrm{c}$ and d) is nearly identical between $n=2$ and $n=3$ at the first iteration. By the second iteration, details of flow gradients in the shallow axial region begin to affect predictions most notably in the shallow lithosphere, although limited model resolution likely impacts this result (see Section 4). More modest differences develop below the lithosphere where anisotropy for the $n=3$ case is predicted to be somewhat stronger than for the $n=2$ case (Figs $4 \mathrm{e}$ and $\mathrm{f}$ ). Since the sense and general scale of asthenospheric changes between linear and nonlinear cases for $n=3$ follows those for $n=2$, we proceed to full coupling using $n=2$, which requires significantly less computing time than case $n=3$ while still providing opportunity to assess flow/CPO/seismic anisotropy feedbacks for more realistic olivine polycrystal behaviour.

Subsequent iteration indicates that feedbacks associated with anisotropic rheology are notable for polycrystals with power-law 


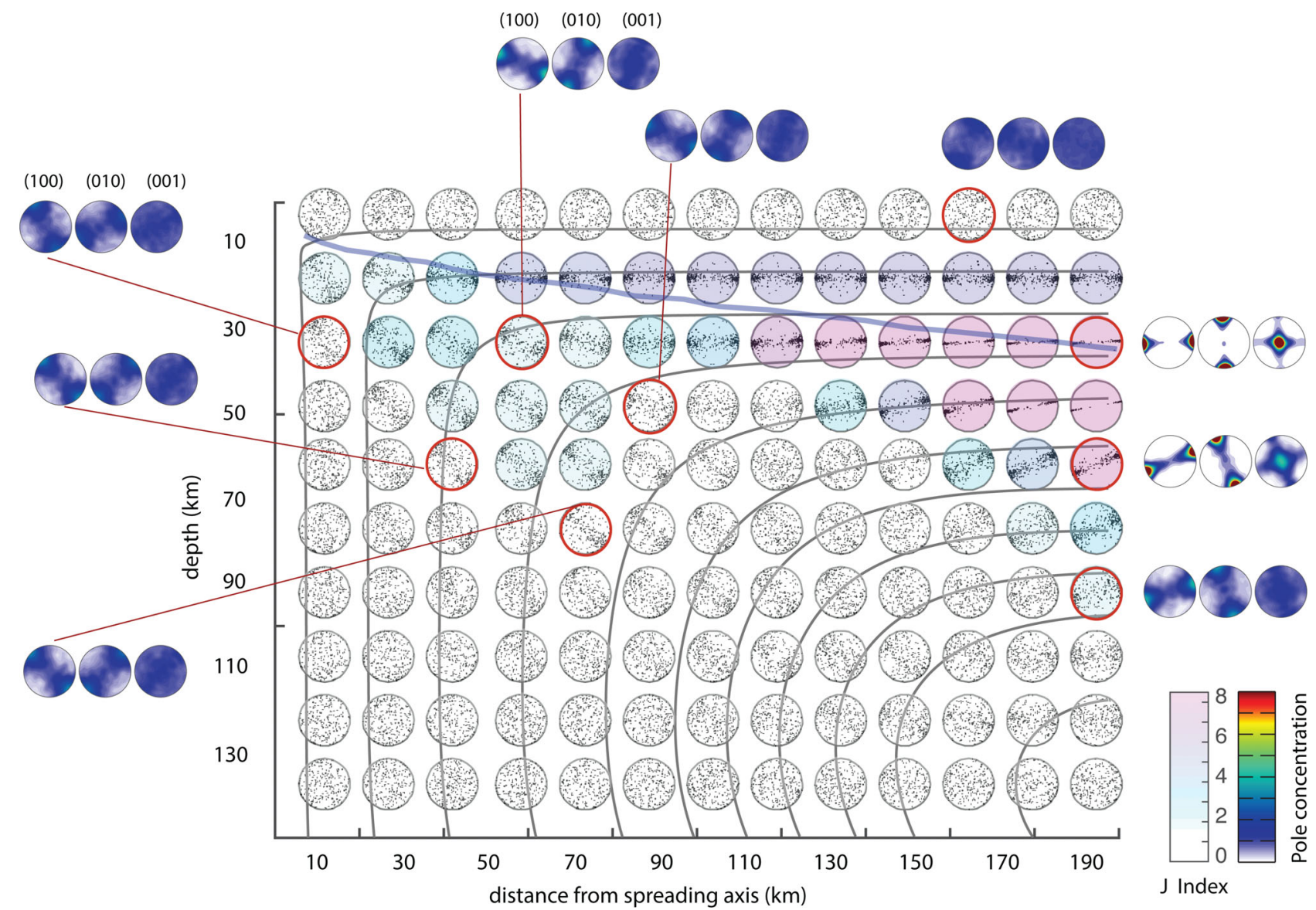

Figure 5. Fully coupled, power-law $(n=2)$ polycrystal flow field and CPO, at iteration 5. Format and colour scales are the same as Fig. 1, with $a$-axis pole figures shown throughout the model, colour shaded by $J$ index. At select locations, pole concentrations for all three olivine axes are shown.

behaviour. By the fifth iteration, the flow field has changed relative to the reference model in the same sense that the linear polycrystal had at iteration 15, although surpassing the sharpening of the corner somewhat (Supporting Information Fig. S1). The strength of the CPO is higher in key regions (Fig. 5), $J$ Index is slightly reduced in the shallow, near-axis corner region of flow but values increase to 5-7 in the lower lithosphere beyond $50 \mathrm{~km}$ from the axis. A band of high values ( $J$ index 8 and greater) extends $30-40 \mathrm{~km}$ below the base of the lithosphere persists off axis from $x=100 \mathrm{~km}$ onward. Subhorizontal fast axis pole concentrations are more than twice as high just beneath the base of the lithosphere by $20 \mathrm{Myr}$ and $b$-axis poles there are concentrated at vertical. $C$-axes cluster in the direction perpendicular to spreading, although with distance below the lithosphere the $c$-axis distribution broadens (and is rotated somewhat) to include girdles in subhorizontal and subvertical planes.

Given the significant computation time required and the fact that patterns are being reinforced with each iteration performed, we are confident that our results thus far are a reliable indicator of the scale of feedbacks due to CPO-based anisotropic viscosity despite the fact that the flow/CPO/viscosity have not yet converged to a fully selfconsistent solution for the power-law polycrystal case. Differences in the predicted velocity field between $n=2$, iterations 4 and 5 are, however, modest, not exceeding 2 per cent of the specified spreading rate (twice our convergence criteria) in part of the axial region of the model $(x, z<15 \mathrm{~km})$. A band that thickens below the lithosphere in the off-axis region still shows $1-2$ per cent change in predicted velocity between these iterations.
The viscosity tensor variability for fully coupled, $n=2$ cases is stronger than for the linear polycrystal. A narrow subaxial region deviates from isotropic values for several of the tensor components (Figs $3 \mathrm{c}$ and d). A stronger deviation occurs at the base and immediately below the lithosphere in most tensor components (Fig. $3 \mathrm{~d}$ ).

The body wave signature predicted for the fully coupled, $n=2$ case (Fig. 6) is stronger than for the intermediate coupling case, with off-axis splitting $\sim 1.2 \mathrm{~s}$ at $20 \mathrm{Myr}$ compared to $\sim 0.6 \mathrm{~s}$. This difference is within detection limits for discrimination using a quiet, well-oriented ocean bottom seismometer station (Wolfe \& Solomon 1998) but is near the limit for noisy stations or small data sets (Bodmer et al. 2015; Menke et al. 2015). Reduced anisotropy within $\sim 75 \mathrm{~km}$ of the axis might be discernible, and a dense station spacing across the plate boundary with analysis of both $P$ and $S$ waves could help discriminate between models.

Predicted surface wave anisotropy differs more strongly between the intermediate coupling case and the power law, fully coupled case (Fig. 7). Surface waves of different frequencies sense structure at depth differently (Fig. 7b), so the frequency-dependent phase velocity and its azimuthal dependence are excellent diagnostics for anisotropy that varies with depth. Azimuthal variations are relatively small for Rayleigh waves at $10 \mathrm{mHz}$ that reach deep into the asthenosphere and beyond. Although azimuthal anisotropy of 2 per cent should be a statistically significant, observable signal, we do not expect that the difference in effect from the three cases shown here is resolvable (Fig. 7c). However, at higher frequencies (for which measurement errors are typically smaller than for $10 \mathrm{mHz}$ ) the difference in impact on phase velocity becomes much stronger. 

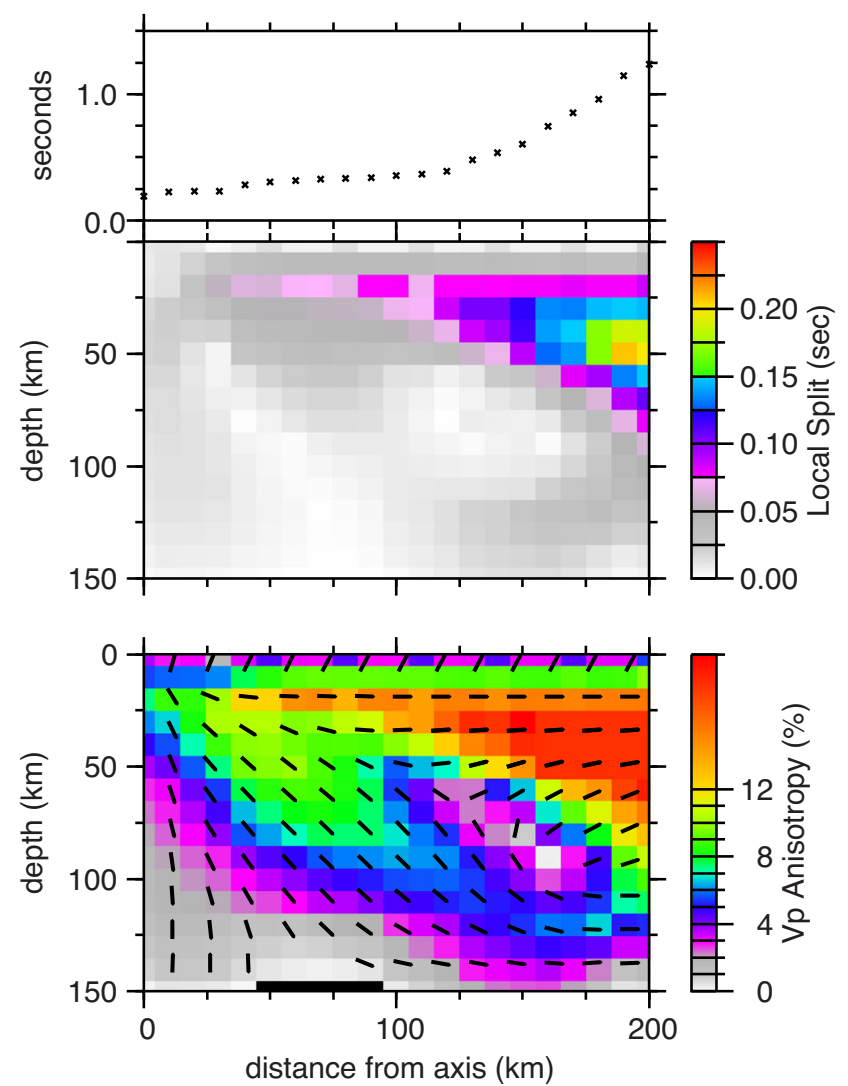

Figure 6. Body wave anisotropy predicted for fully coupled, power-law polycrystal $(n=2$, it5) case. Top panel shows SKS splitting time. Middle panel shows local splitting for vertically incident shear wave. Lower panel shows local $P$-wave anisotropy magnitude (colour) and fast direction (vectors).

In particular, the effects from the fully coupled, power law $(n=2)$ polycrystal stand out clearly from those of the other shown cases.

For weakly anisotropic media, the azimuthal dependence of the frequency-dependent phase velocity perturbation with respect to a reference velocity, $\delta \mathrm{c} / \mathrm{c}(\omega)$ can be described by a truncated trigonometric series (Smith \& Dahlen 1973)

$$
\begin{aligned}
\delta c / c(\omega, \psi)= & a_{0}(\omega)+a_{1}(\omega) \cos 2 \psi+a_{2}(\omega) \sin 2 \psi \\
& +a_{3}(\omega) \cos 4 \psi+a_{4}(\omega) \sin 4 \psi,
\end{aligned}
$$

where $\psi$ is the azimuth, and $a_{n}(\omega), n=0-4$, are frequencydependent depth-integrals over structure, containing sensitivity kernels similar to those shown in Fig. 7(b). In realistic anisotropic media, $a_{1}$ and $a_{2}$ are expected to dominate for Rayleigh waves (e.g. Smith \& Dahlen 1973; Montagner \& Nataf 1986). In our intermediate coupling case, and for Rayleigh waves at $30 \mathrm{mHz}, a_{1}$ is on the order of 1 per cent while the other coefficients are at least 2 orders of magnitude smaller. This holds also for the other cases though $a_{1}$ is larger (2.6 per cent for fully coupled, $n=2$, iteration 5 case). Hence, we are confident that the results we present here would yield observable differences in Rayleigh wave azimuthal anisotropy.

Love wave anisotropy was also computed, for which the $4 \Psi$ terms are expected to dominate. Indeed, for the intermediate coupling case, $a_{3}$ dominates but is on the order of 0.2 per cent, while the next-largest coefficient, $a_{1}$, is 10 times smaller. The fully coupled, $n=2$, iteration 5 case yields an $a_{3}$ on the order of 2 per cent, with the next-largest coefficients 100 times smaller. While the strength of anisotropy is certainly measurable (Fig. 7c, dashed curves), the azimuthal dependence would be difficult to observe and characterize, given the uneven global seismicity. However, as for Rayleigh waves, ignoring azimuthal anisotropy in the interpretation of phase velocity observations would lead to biased structural models.

The von Mises equivalent, or effective, polycrystal strain rates for the fully coupled, power-law model differs notably from that predicted for isotropic viscosity (Fig. 8). Effective deformation rates in the upwelling zone are reduced compared to the constant viscosity case. CPO is somewhat reduced in this zone (Fig. 5 versus Fig. 1, $J$ Index) and the degree of texture-related hardening is less. Off axis $(x>70 \mathrm{~km})$, there are significantly higher strain rates in a zone below the lithosphere that thickens with age of the overlying plate, to about $60 \mathrm{~km}$ depth by $20 \mathrm{Ma}$. This enhanced deformation reflects directional weakening, and dominant activity of the (010)[100] slip system (Supporting Information Fig. S2), associated with the CPO that has developed.

Our use of the same relative critical resolved shear stresses for both the linear and power-law polycrystal (Table 1 shows our 1:10 ratio for relative ease of slip along the $a: c$ axes) means that glide along the $c$-axis is about three times harder than would commonly be assumed for olivine. While this predicts textures that are somewhat less strong than a 1:3 ratio would at the edge of our model, the orientation distribution is essentially the same (Supporting Information Fig. S3) and that is a key factor for the nature of anisotropy in the effective viscosity.

\section{DISCUSSION}

We find that there are feedbacks between anisotropic viscosity associated with CPO and the flow field in the upper mantle. For plate-driven flow at a spreading centre, with background viscosity of about $10^{20} \mathrm{~Pa} \mathrm{~s}$, the overall pattern is still essentially a corner flow but upwelling rate in the subaxial zone is somewhat reduced. This could result in decreased partial melting. Material starting within the subaxial zone $(x<50 \mathrm{~km})$ rises to a level that is a few $\mathrm{km}$ shallower when texture-based anisotropic rheology is incorporated. Our models show that material starting at depth outside the subaxial zone rises as much as $\sim 20 \mathrm{~km}$ shallower, and at higher rates near the inflection point where the flow turns the corner (Figs 1 and 5, and Supporting Information Fig. S1a). This could broaden the low per cent partial melting zone compared to the isotropic (scalar) viscosity case. Our horizontal-only velocity boundary condition at the right side may influence the latter prediction somewhat; a more realistic condition would be the analytic corner flow solution below the base of the rigid lithosphere (Blackman et al. 1996, 2002). This setting does not control the main result on scale of feedback.

The distribution of CPO differs from past linked flow/anisotropy analyses in strength and alignment direction in key regions of the model space when full coupling and anisotropic rheology are employed. The power-law polycrystal alignment direction in the lithosphere is predicted to be horizontal, rather than inclined. This reflects near-axis differences in the stress field just below the base of the lithosphere. As off-axis shearing becomes dominant, the sublithospheric region develops horizontal preferred direction rather than retaining a diffuse version of the inclined alignment that develops in the flow corner. The strength of the off axis CPO is greater than predicted for the intermediate coupling case but for mantle beneath several Myr old oceanic crust the difference in the anisotropy accrued by body waves transiting the upper 100-200 km of the mantle is modest.

While the detailed CPO that we predict reflects on our simplifying assumption that dislocation glide controls the texture development, 
(a)

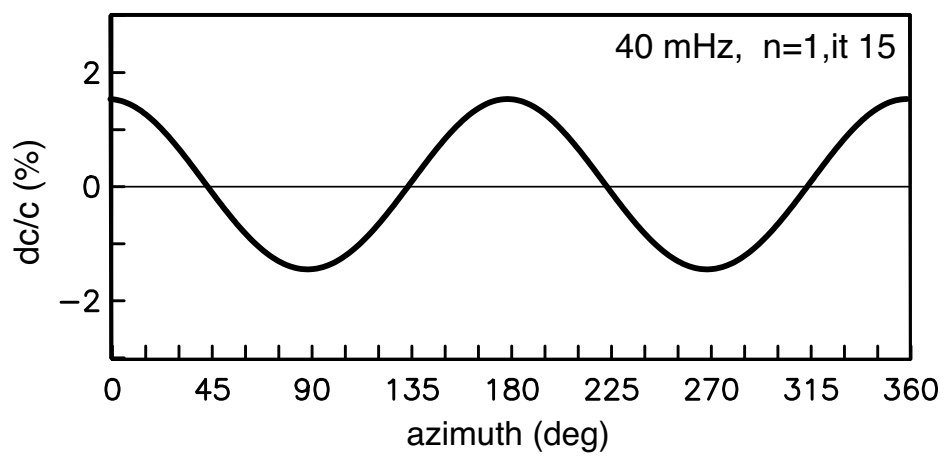

(c)

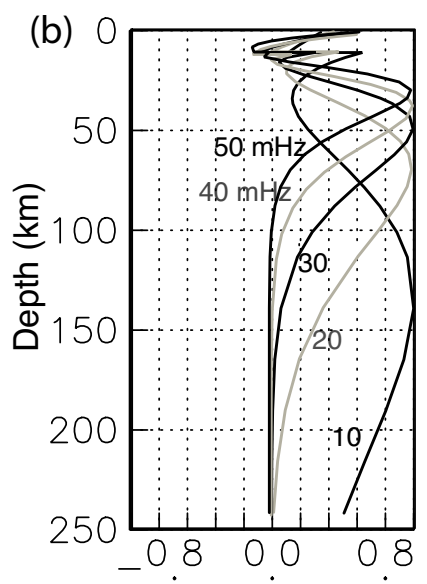

Normalized Vs Sensitivity

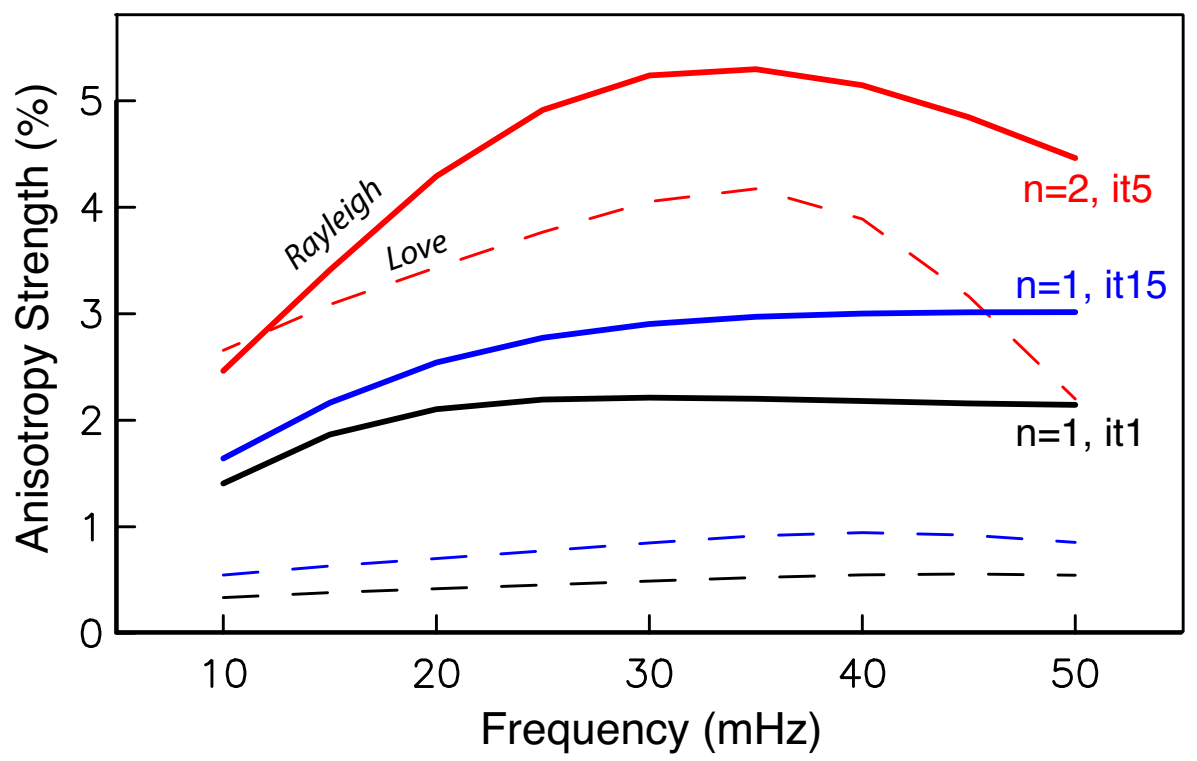

Figure 7. Surface wave anisotropy predicted for different flow/CPO models. (a) Azimuthal variation for $40 \mathrm{mHz}$ Rayleigh wave for the fully coupled, linear polycrystal case; $0^{\circ}$ is spreading direction. (b) Sensitivity kernels for different frequency Rayleigh waves. (c) Magnitude of Rayleigh (solid line) and Love (dashed) wave anisotropy as a function of frequency for three models, as labelled.
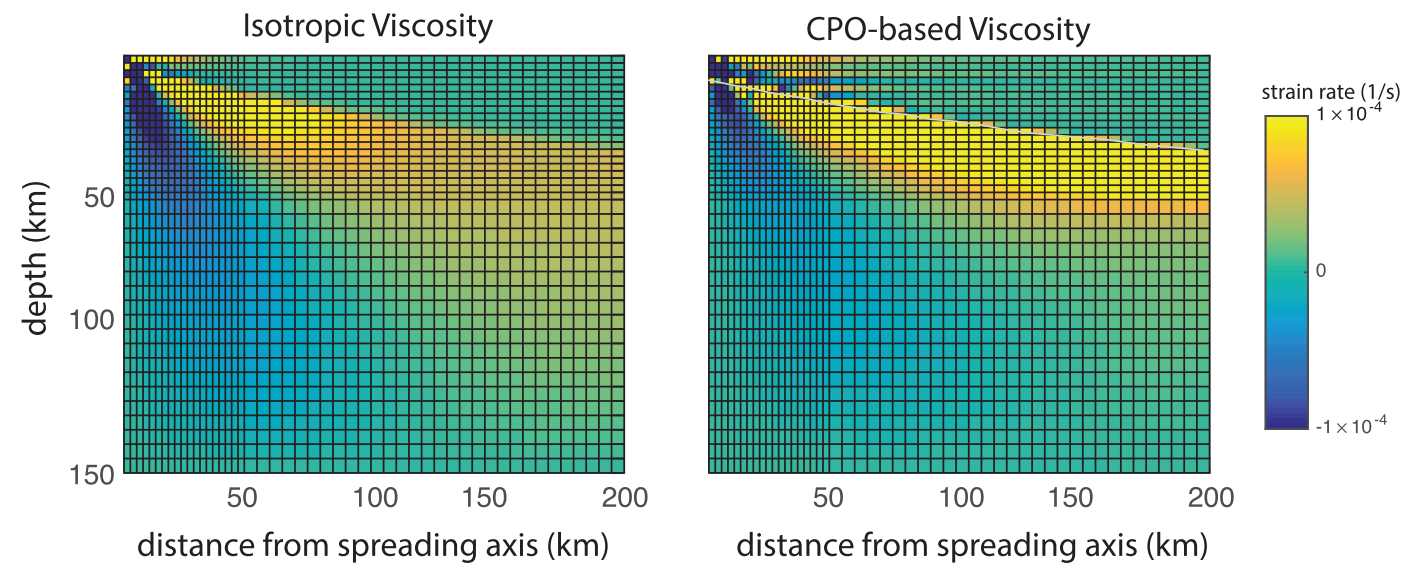

Figure 8. Shear strain rate predicted for the corresponding flow fields. (a) Isotropic viscosity case. (b) Fully coupled CPO-based viscosity case with power-law polycrystal $\left(n=2\right.$, iteration 5). Thick grey line shows base of lithosphere $\left(1000^{\circ} \mathrm{C}\right.$ isotherm). 
the nature of the feedback between flow and anisotropic rheology whose scale is based on CPO is a result that should hold when a more complete set of texturing mechanisms is considered. This is partly due to the fact that our predicted CPOs have a range that is in line with those observed in natural samples, where a suite of mechanisms operated (Mainprice et al. 2000). The applicability also reflects the fact that recrystallized grains can align similar to their parent grain in some conditions (Zhang et al. 2000) when melt is not present (Holtzman et al. 2003; Higgie \& Tommasi 2012, 2014). Inclusion of dislocation climb in a prior calculation as a secondary deformation mechanism (Lebensohn et al. 2010), only slightly altered the CPO as climb did not contribute significantly to the overall polycrystal deformation. $J$ indices that we obtain in the off-axis region beneath the lithosphere, where uniaxial extension in the corner of the flow is followed by plate-driven shear, are generally of the order of those determined in recent experimental samples where applied deformation was designed to investigate this scenario (Hansen et al. 2016). The very strongest predicted textures near an off-axis portion of the lithosphere base in our fully coupled, power-law polycrystal model do exceed this $J=11-20$ range, suggesting that more complete modelling of deformation mechanisms (including climb and recrystallization) in this region may be warranted.

Details of the rapidly changing stress field near the base of the axial lithosphere strongly impact the CPO that locks into the shallow lithosphere as it cools. Our modelling provides a very rough indication of this part of the system. The results are useful for gauging the extent of CPO influence on evolution as material completes its rise and begins to cool and eventually become part of the essentially rigid plate. However, the $\mathrm{CPO}$ predicted for the shallowest part of our models should be viewed as illustrative of the range in alignments and strengths that could occur, rather than quantitatively. Several simplifications were employed to meet the goals of this study. We set a single temperature $\left(1000{ }^{\circ} \mathrm{C}\right)$ for when plastic deformation ceases, rather than adjusting slip system activity over a cooling range. We set a stepwise increase in overall viscosity (scaling by a factor of $10^{3}$ ) at this temperature as well. Initial runs excluded temperature $(T)$ dependence of viscosity in an effort to isolate the effects of CPO on viscosity but a stable solution was not obtained. The flow pattern and CPO cycled through 4-5 states over successive iterations and did not settle into stable distributions that could be reliably interpreted. Since the general $T$ dependence of mantle rheology is well known (Turcotte \& Schubert 1982), even if details at temperatures in the $700-1200{ }^{\circ} \mathrm{C}$ range are still being assessed (Demouchy et al. 2009), we re-introduced a simple $T$ dependence in the models that gives the lithosphere rigidity (as done in Blackman et al. 2002). This resulted in stable, self-consistent results in 1215 iterations. Model discretization can play a role in behaviour in the high gradient near-axis region. Local velocity gradients at each step along a streamline drive the plastic deformation, so numerical artefacts can impact the outcome or make convergence more difficult. Early tests of model resolution (Blackman 2013) showed that velocity gradients near the tight shallow flow corner and the base of the rigid lithosphere have numerical oscillations for element size greater than $0.5-0.75 \mathrm{~km}$ in the axial and lithosphere region (Supporting Information Fig. S4). While general CPO patterns are not highly sensitive to this noise, steps in the lithosphere base can introduce more consistent local differences in flow gradients that make the effective local strain rate jittery (Fig. 8 and Supporting Information Fig. S2). Moving to a more highly refined FEM mesh for future modelling will be important for quantitative evaluation of the predicted lithosphere anisotropy.
A larger model region will also be needed to quantify seismic differences between models, with off-axis shearing more fully developed so that the depth extent (thickening rate) of the significantly aligned region is more clear. To be computationally feasible, this will require the next step of implementation- storing element CPO at each iteration and backtracking only to a prior element position, rather than all the way to the model base. Our full streamline results will be useful for testing the details of this implementation (e.g. how far to backtrack, intra-element variability, along-streamline strain increment sensitivity).

\section{CONCLUSIONS}

Olivine polycrystals that deform via dislocation glide develop CPO that results in their viscosity being anisotropic. The associated directional dependence in strength impacts the pattern of upper-mantle flow near a plate boundary. For background asthenosphere viscosity of $\sim 10^{20} \mathrm{~Pa}$ s and a rigid lithosphere, the anisotropic viscosity modification of the corner flow pattern is not drastic, but the sense of the change could affect partial melting rates and distribution. Feedback is also predicted in the development of CPO, particularly near and below the base of the lithosphere. Notably stronger fabric is predicted below the flanks of a spreading centre for fully coupled, power-law polycrystals than was determined using prior intermediate coupling polycrystal approaches. Alignment in the lithosphere is stronger and rotates into the horizontal. CPO near the corner inflection point of the flow field is reduced. These are important local behaviours from a structural viewpoint. The associated SKS splitting is modestly different $(\sim 0.5 \mathrm{~s})$ between the intermediate and fully coupled cases for oceanic plates less than $20 \mathrm{Myr}$ old. Surface waves, on the other hand, show a more notable difference between the cases, with the amount of Rayleigh wave azimuthal anisotropy being twice as large (up to 5 per cent) for fully coupled power-law flow/polycrystals compared to predictions for linear, intermediate coupled flow/polycrystals.

\section{ACKNOWLEDGEMENTS}

This study was funded by NSF proposal EAR-1141934. DKB also received support for work on this project from NSF via the Individual Research/Development programme during a rotation as programme manager in OCE. The viscosities and elastic constants calculated for any of the models herein are available to interested users at any time (contact dblackman@ucsd.edu). The Isaiah code is also available (contact prd@cornell.edu). The authors are happy to discuss the formats and use of these resources and will provide files/code upon request. Pole figure contouring and J Index calculations were done using MTEX, Version 4.0.23 http://code.google.com/p/mtex/ and thanks go to B. Ildefonse for guidance getting started with those routines. A. Tommasi and an anonymous reviewer provided many helpful comments which contributed to improve reporting of this study.

\section{REFERENCES}

Anderson, O.L. \& Isaak, D.B., 1995. Elastic constants of mantle minerals at high temperature, in Global Earth Physics: A Handbook of Physical Constants, pp. 64-97, ed. Ahrens, T.J., American Geophysical Union.

Bai, Q., Mackwell, S.J. \& Kohlstedt, D.L., 1991. High-temperature creep of olivine single crystals, 1. Mechanical results for buffered samples, J. geophys. Res., 96, 2441-2463. 
Becker, T.W., Chevrot, S., Schulte-Pelkum, V. \& Blackman, D.K., 2006a. Statistical properties of seismic anisotropy predicted by upper mantle geodynamic models, J. geophys. Res., 111, doi:10.1029/2005JB004095.

Becker, T.W., Schulte-Pelkum, V., Blackman, D.K., Kellogg, J.B. \& O'Connell, R.J., 2006b. Mantle flow under the western United States from shear wave splitting, Earth planet. Sci. Lett., 247, 235-251.

Ben Ismaill, W. \& Mainprice, D., 1998. An olivine fabric database: an overview of upper mantle fabrics and seismic anisotropy, Tectonophysics, 296, 145-157.

Birch, F., 1960. The velocity of compressional waves in rocks to 10 kilobars, J. geophys. Res. 65, 1083-1102.

Blackman, D.K., 2013. Anisotropic mantle flow at spreading centersseismic and rheologic effects, in IASPEI General Assembly, Gothenburg, Abstract and Poster.

Blackman, D.K. \& Kendall, J.-M., 1997. Sensitivity of teleseismic body waves to mineral texture and melt in the mantle beneath a mid-ocean ridge, Phil. Trans. R. Soc. A, 355, 217-231.

Blackman, D.K. \& Kendall, J.-M., 2002. Seismic anisotropy in the upper mantle: 2. Predictions for current plate boundary flow models, Geochem. Geophys. Geosyst., 3(9), 8602, doi:10.1029/2001GC000247.

Blackman, D.K., Kendall, J.-M., Dawson, P.R., Wenk, H.-R., Boyce, D. \& Phipps Morgan, J., 1996. Teleseismic imaging of subaxial flow at midocean ridges: travel-time effects of anisotropic mineral texture in the mantle, Geophys. J. Int., 127, 415-426.

Blackman, D.K., Wenk, H.-R. \& Kendall, J.-M., 2002. Seismic anisotropy in the upper mantle: 1. Factors that affect mineral texture and effective elastic properties, Geochem. Geophys. Geosyst., 3, 8601, doi:10.1029/2001GC000248.

Bodmer, M., Toomey, D.R., Hooft, E.E., Nábelek, J. \& Braunmiller, J., 2015. Seismic anisotropy beneath the Juan de Fuca plate system: evidence for heterogeneous mantle flow, Geology, 43(12), 1095-1098.

Boneh, Y., Morales, L.F.G., Kaminski, E. \& Skemer, P., 2015. Modeling olivine CPO evolution with complex deformation histories-implications for the interpretation of seismic anisotropy in the mantle, Geochem. Geophys. Geosyst., 16, 3436-3455.

Boyce, D.E. \& Dawson, P.R., 2014a. Simulations of the transport and distortion of foil markers in friction stir welding, eCommons (Cornell OpenAccess Repository), Materials Processing Collection.

Boyce, D. \& Dawson, P., 2014b. A methodology to determine tooling interface temperature and traction conditions from measured force and torque in materials processing simulations based on multimesh error estimation. arXiv:1403.7822v1(cond-mat:mtrl-sci).

Carter, N.L., 1976. Steady state flow of rock, Rev. Geophys. Space Phys., 14, 301-360.

Castelnau, O., Blackman, D.K., Lebensohn, R.A. \& Castañeda, P.P., 2008. Micromechanical modeling of the viscoplastic behavior of olivine, J. geophys. Res., 113, doi:10.1029/2007JB005444.

Castelnau, O., Blackman, D.K. \& Becker, T.W., 2009. Numerical simulations of texture development and associated rheological anisotropy in regions of complex mantle flow, Geophys. Res. Lett., 36, L12304 doi:10.1029/2009GL038027.

Chastel, T.B., Dawson, P.R., Wenk, H.-R. \& Bennett, K., 1993. Anisotropic convection with implications for the upper mantle, J. geophys. Res., 98, $17757-17771$.

Cho, J.-H. \& Dawson, P.R., 2008. Modeling texture evolution during friction stir welding of stainless steel with comparison to experiments, J. Eng. Mater. Technol., 130, doi:10.1115/1.2816902.

Cho, J.-H., Boyce, D.E. \& Dawson, P.R., 2007. Modelling of strain hardening during friction stir welding of stainless steel, Modelling Simul. Mater. Sci. Eng., 15, 469-486.

Christensen, U.R., 1987. Some geodynamical effects of anisotropic viscosity, Geophys. J. Int., 91, 711-736.

Dawson, P. \& Wenk, H., 2000. Texturing of the upper mantle during convection, Phil. Mag. A, 80, 573-598.

Demouchy, S., Schneider, S.E., Mackwell, S.J., Zimmerman, M.E. \& Kohlstedt, D.L., 2009. Experimental deformation of olivine single crystals at lithospheric temperatures, Geophys. Res. Lett., 36, L04304, doi:10.1029/2008GL036611.
Detrez, F., Castelnau, O., Cordier, P., Merkel, S. \& Raterron, P., 2015. Effective viscoplastic behavior of polycrystalline aggregates lacking four independent slip systems inferred from homogenization methods; application to olivine, J. Mech. Phys. Solids, 83, 199-220.

Gilbert, F. \& Dziewonski, A.M., 1975. An application of normal mode theory to the retrieval of structural parameters and source mechanisms from seismic spectra, Phil. Trans. R. Soc. A, 278, 187-269.

Goetze, C. \& Kohlstedt, D.L., 1973. Laboratory study of dislocation climb and diffusion in olivine, J. geophys. Res., 78, 5961-5971.

Goulding, N.J., Ribe, N.M., Castelnau, O., Walker, A.M. \& Wookey, J., 2015. Analytical parameterization of self-consistent polycrystal mechanics: fast calculation of upper mantle anisotropy, Geophys. J. Int., 203, 334-350.

Hadjazian, N., Garel, F., Davies, D.R. \& Kaminski, E., 2017. Ageindependent anisotropy under oceanic plates explained by strain history in the asthenosphere, Earth planet. Sci. Lett., 460, 135-142.

Hansen, L.N., Zimmerman, M.E. \& Kohlstedt, D.L., 2012. Laboratory measurements of the viscous anisotropy of olivine aggregates, Nature, 492(7429), 415-418.

Hansen, L.N., Warren, J.M., Zimmerman, M.E. \& Kohlstedt, D.L., 2016. Viscous anisotropy of textured olivine aggregates, Part 1: Measurement of the magnitude and evolution of anisotropy, Earth planet. Sci. Lett., 445, 92-103.

Higgie, K. \& Tommasi, A., 2012. Feedbacks between deformation and melt distribution in the crust-mantle transition zone of the Oman ophiolite, Earth planet. Sci. Lett., 359-360, 61-72.

Higgie, D. \& Tommasi, A., 2014. Deformation in a partially molten mante: Constraints from plagioclase lherzolites from Lanzo, western Alps, Tectonophysics, 615-616, 167-181.

Hirth, G. \& Kohlstedt, D.L., 2003. Rheology of the upper mantle and the mantle wedge: a view from the experimentalists, in Inside the Subduction Factory, Geophys. Monogr. Ser., vol. 138, pp. 83-105, ed. Eiler, J., AGU.

Holtzman, B.K. \& Kendall, J.-M., 2010. Organized melt, seismic anisotropy, and plate boundary lubrication, Geochem. Geophys. Geosyst., 11, Q0AB06, doi:10.1029/2010GC003296.

Holtzman, B.K., Groebner, N., Zimmerman, M.E., Ginsberg, S.B. \& Kohlstedt, D.L., 2003. Stress-driven melt segregation in partially molten rocks, Geochem. Geophys. Geosyst., 4(5), 8607, doi:10.1029/2001GC000258.

Honda, S., 1986. Strong anisotropic flow in a finely layered asthenosphere, Geophys. Res. Lett., 13, 1454-1457.

Jha, K., Parmentier, E.M. \& Phipps Morgan, J., 1994. The role of mantledepletion and melt-retention buoyancy in spreading center segmentation, Earth planet Sci. Lett., 125, 221-234.

Kaminski, E. \& Ribe, N.M., 2002. Timescales for the evolution of seismic anistoropy in mantle flow, Geochem. Geophys. Geosyst., 3, doi: 10.1029/2001GC000222.

Karato, S., 2008. Deformation of Earth Materials: An Introduction to the Rheology of Solid Earth, pp. 463, Cambridge Univ. Press.

Lebensohn, R.A., Liu, Y. \& Castañeda, P.P., 2004. Macroscopic properties and field fluctuations in model power-law polycrystals: fullfield solutions versus self-consistent estimates, Proc. R. Soc. A, 460, 1381-1405.

Lebensohn, R.A., Tomé, C.N. \& Ponte Castañeda, P., 2007. Self-consistent modeling of the mechanical behavior of viscoplastic polycrystals incorporating field fluctuations, Phil. Mag., 87(28), 4287-4322.

Lebensohn, R.A., Hartley, C.S., Tomé, C.N. \& Castelnau, O., 2010. Modeling the mechanical response of polycrystals deforming by climb and glide, Phil. Mag., 90, 567-583.

Lebensohn, R.A., Zecevic, M., Knezevic, M. \& McCabe, R.J., 2016. Average interagranular misorienation trends in polycrystalline material predicted by a viscoplastic self-consistent approach, Acta Mater., 104, 228-236.

Lee, Y.-S., Dawson, P.R. \& Dewhurst, T.B., 1990. Bulge predictions in steady state bar rolling processes, Int. J. Numer. Methods Eng., 30, 1403-1413.

Lev, E. \& Hager, B.H., 2008. Prediction of seismic anisotropy from flow models: a comparison of three methods, Geochem. Geophys. Geosyst., 9, doi: $10.1029 / 2008 \mathrm{GC} 002032$.

Li, Z.-H., Di Leo, J.F. \& Ribe, N.M., 2014. Subduction-induced mantle flow, finite strain, and seismic anisotropy: numerical modeling, J. geophys. Res., 119, 5052-5076. 
Long, M.D. \& Becker, T.W., 2010. Mantle dynamics and seismic anisotropy, Earth planet. Sci. Lett., 297, 341-354.

Mainprice, D., Barroul, G. \& Ismaill, W.B., 2000. The seismic anisotropy of the Earth's mantle: from single crystal to polycrystal, in Earth's Deep Interior, Geophysical Monograph 117, pp. 237-264, eds Karato, S.-I., Forte, A., Liebermann, R., Masters, G. \& Strixrude, L., AGU.

McKenzie, D., 1979. Finite deformation during fluid flow, Geophys. J. R. astr. Soc., 58, 689-715.

Menke, W., Zha, Y., Webb, S.C. \& Blackman, D.K., 2015. Seismic anisotropy indicates ridge-parallel asthenospheric flow beneath the Eastern Lau Spreading Center, J. geophys. Res., 120(2), 976-992.

Montagner, J.-P. \& Nataf, H.-C., 1986. A simple method for inverting the azimuthal anisotropy of surface waves, J. geophys. Res., 91, 511-520.

Mülhaus, H.-B., Moresi, L. \& Cada, M., 2004. Emergent anisotropy and flow alignment in viscous rock, Pure appl. Geophys., 161, 2451-2463.

Nicolas, A. \& Christensen, N.I., 1987. Formation of anisotropy in upper mantle peridotites - a review, in Composition, Structure and Dynamics of the Lithosphere-Asthenosphere System, AGU Geodynamics Series, vol. 16, pp. 111-124, eds Fuchs, K. \& Froidvaux, C., American Geophysical Union.

Nicolas, A. \& Poirier, J.P., 1976. Crystalline Plasticity and Solid-state Flow in Metamorphic Rocks, John Wiley.

Nicolas, A. \& Violette, J.F., 1982. Mantle flow beneath oceanic ridges: models derived from ophiolites, Tectonophysics, 81, 319-339.

Olugboji, T.M., Park, J., Karato, S.-I. \& Shinohara, M., 2016. Nature of the seismic lithosphere-asthenosphere boundary within normal oceanic mantle from high-resolution receiver functions, Geochem. Geophys. Geosyst., 17, 1265-1282.

Ponte Castañeda, P., 2002. Second-order homogenization estimates for nonlinear composites incorporating field fluctuations. I. Theory, J. Mech. Phys. Solids, 50, 737-757.

Raterron, P., Amiguet, E., Chen, J., Li, L. \& Cordier, P., 2009. Experimental deformation of olivine single crystals at mantle pressure and temperature, Phys. Earth planet. Inter., 172, 74-83.

Raterron, P., Detrez, F., Castelnau, O., Bollinger, C., Cordier, P. \& Merkel, S., 2014. Multiscale modeling of upper mantle plasticity: from single-crystal rheology to multiphase aggregate deformation, Phys. Earth planet. Inter, 228, 232-243.

Ribe, N.M., 1989. Seismic anisotropy and mantle flow, J. geophys. Res., 94, 4213-4223.

Signorelli, J. \& Tommasi, A., 2015. Modeling the effect of subgrain rotation recrystallization on the evolution of olivine crystal preferred orientations in simple shear, Earth planet. Sci. Lett., 430, 356-366.

Smith, M.L. \& Dahlen, F.A., 1973. The azimuthal dependence of Love and Rayleigh wave propagation in a slightly anisotropic medium, J. geophys. Res., 78, 3321-3333.

Tanimoto, T., 1986. Free oscillations of a slightly anisotropic earth, Geophys. J. R. astr. Soc., 87, 493-517.

Tommasi, A., 1998. Forward modling of the development of seismic anisotropy in the upper mantle, Earth planet. Sci. Lett., 160, 1-13.

Tommasi, A., Mainprice, D., Cannova, G. \& Chastel, Y., 2000. Viscoplastic self-consistent equilibrium modeling of olivine lattice preferred orientations: implications for the upper mantle seismic anisotropy, J. geophys. Res., 105, 7893-7908.

Turcotte, D.L. \& Schubert, G., 1982. Geodynamics, John Wiley \& Sons.

Wenk, H.-R., Bennett, K., Canova, G.R. \& Molinari, 1991. Modelling plastic deformation of peridotite with the self-consistent theory, J. geophys. Res., 96, 8337-8349.

Wessel, P. \& Smith, W.H.F., 1998. New, improved version of the generic mapping tools, EOS, Trans. Am. geophys. Un., 79(47), 579, doi:10.1029/98EO00426.

Wolfe, C.J. \& Solomon, S.C., 1998. Shear-wave splitting and implications for mantle flow beneath the MELT region of the East Pacific Rise, Science, 280, $1230-1232$.

Woodhouse, J.H., 1988. The calculation of eigenfrequencies and eigenfunctions of the free oscillations of the earth and the sun, in Seismological
Algorithms, Computational Methods and Computer Programs, pp. 321370, ed. Doornbos, D.J., Academic Press.

Zhang, S., Karato, S., Gerald, J.F., Faul, U.H. \& Zhou, Y., 2000. Simple shear deformation of olivine aggregates, Tectonophysics, 316, 133-152.

\section{SUPPORTING INFORMATION}

Supplementary data are available at $G J I$ online.

Figure S1. Comparison of model results. Top shows flowlines predicted for three different models: isotropic viscosity (black); fully coupled, linear polycrystal case (green, iteration 15); and the fully coupled, power-law polycrystal case (red, $n=2$, iteration 5). Bottom shows strain rate for the fully coupled, linear polycrystal case (iteration 15), which can be compared to the other two models (Fig. 8).

Figure S2. Activity of the specified olivine slip systems as a polycrystal evolves along a flowline. Representative asthenosphere flow paths are shown throughout the fully coupled, power-law model, colour coded by path (upper left panel). The upper right panel shows the step number at which each flowline turns the corner, from subvertical flow to horizontal flow. The lower four panels show evolution of slip system activity along the flowlines. The fourth, false system is shown in the bottom panel, with vertical scale that is an order of magnitude smaller than used in the plots of the other, standard slip systems. Jagged portions of the cyan and green curves illustrate numerical sensitivity in regions of high velocity gradient.

Figure S3. Comparison of texture predicted for different assumptions of the relative ease of slip along $a$ versus $c$ axes of olivine (Table 1). The rightmost column shows $a$-axis pole figures for the fully coupled power-law polycrystal run reported in this paper ( $n=2$, iteration 5), for three streamlines that end at the right edge of the model at different depths near/below the base of the lithosphere. Immediately to the left, contoured pole concentrations for all three axes are shown for the same case. Results for a more typical 1:3 ratio of $a: c$ critical resolved shear stress value are shown by the left four columns. Colour scale is constant, $J$ index for each streamline and case is labelled.

Figure S4. Model discretization and effects on near-axis flow velocity, gradients of which control details of CPO that will be frozen into the lithosphere. Upper left panel shows subregions where different mesh size is specified. Lower left panels show the model for which results in this paper are reported-axial element size is $2.5 \mathrm{~km}$ and off-axis it is $5 \mathrm{~km}$. Colour indicates total velocity, maximum is specified spreading rate (SR); yellow box shows zoom area. Flow gradients vary rapidly in the near-axis flow corner and near the base of the young lithosphere, and discretization introduces local artefacts. Lower right panels show model where along-streamline flow gradients are well behaved, thus CPO predictions for streamlines that transit the axial region would be more robust. Here, axial element size is $0.5 \times 0.75 \mathrm{~km}(x \times z)$, and off-axis size is $3 \mathrm{~km}$. Width of the axial zone is decreased to $30 \mathrm{~km}$ in order to keep the total number of elements in the model reasonable.

Please note: Oxford University Press is not responsible for the content or functionality of any supporting materials supplied by the authors. Any queries (other than missing material) should be directed to the corresponding author for the paper. 


\title{
Effects of crystal preferred orientation on upper mantle flow near plate boundaries: Rheologic feedbacks and seismic anisotropy
}

\author{
D.K. Blackman', D.E. Boyce², O. Castelnau³, P.R. Dawson², and G. Laske \\ ${ }^{1}$ Scripps Institution of Oceanography, UCSD, La Jolla, USA
}

\author{
${ }^{2}$ Cornell University, Ithaca NY, USA \\ ${ }^{3}$ PIMM-UMR8006, CNRS, ENSAM, CNAM, Paris, France.
}

\begin{abstract}
Supplementary material provides additional comparison of flow and strain-rate for different models, indication of how slip system activity varies along streamlines for one model, how specified slip system hardness impacts predictions, and how model discretization can affect local velocity gradients in the region near the spreading axis. Text and four figures illustrate these points.
\end{abstract}

The models for which results are reported in this paper have 2000 elements. Velocity (V) and/or traction (T) boundary conditions are specified for the flow calcluation for the $(x, y, z)$ components respectively, with $S R=$ spreading rate: top- $V V V=(S R, 0,0)$; axis- $V T T=(0,0,0)$; base$\mathrm{TTT}=(0,0,0)$; outflow side- $\mathrm{TTV}=(0,0,0)$; front $\&$ back- TVT=(0,0,0). Streamlines ending at each element midpoint are computed and the CPO that evolves along them is determined. At the endpoint, the effective viscosity for the polycrystal with final CPO is computed. The $6 \times 6$ tensor has 6 independent components for the 2-D flow field that we model. These are shown in Figure 3, with spreading direction ( $\mathrm{x}$ ) corresponding to $i j k l$ index value of 1 , and vertical direction (z) corresponding to index value of 3 . Normalization of plotted viscosity value is done 
separately for each tensor component. At each position in the model, the calculated local viscosity tensor component value is divided by the value of that isotropic viscosity tensor component. Thus, Figure 3 shows non-dimensional values.

The activity of the specified slip systems varies as a textured polycrystal is subjected to a constantly evolving stress. Figure S2 illustrates this evolution for several representative flowlines in the asthenosphere for a power law polycrystal case $(n=2$, iteration 3$)$. Table 1 lists the critical resolved shear stress (CRSS) threshold for each slip system within a crystal. Figure S3 illustrates the very modest effect that our simplified assumption for the ratio of a:c axis CRSS has on results. Textures calculated for the specified 1:10 ratio are very similar to those determined for a 1:3 ratio, which would be more typical for power-law olivine polycrystal.

Since CPO is 'frozen' into the lithosphere once $\mathrm{T}$ drops below $1000^{\circ} \mathrm{C}$, lines of constant viscosity are predicted in the shallowest section. While the viscosity tensors we determine (Figure 3) are probably a robust indication of the range that would occur in the lithosphere where CPO controls rheologic anisotropy, the rapidly changing and somewhat oscillatory behavior are influenced by the discretization interval ( $2.5 \mathrm{~km}$ in the axial zone). Element size of 0.5-0.75 km would provide a more reliable prediction of CPO, viscosity, and seismic anisotropy structure within the lithosphere. This is illustrated in Figure S4, where smoothly varying velocity field was computed for the finer mesh while steps in velocity result for larger mesh. Analysis of velocity gradients along streamlines that transit the axial region indicates that numerical oscillation is nearly removed for the smaller node spacing.

\section{Figure Captions.}

Figure S1. Comparison of model results. Top shows flowlines predicted for 3 different models: isotropic viscosity (black), fully coupled, linear polycrystal case (green, iteration 15), and the 
fully coupled, power-law polycrystal case (red, $n=2$, iteration 5). Bottom shows strain rate for the fully coupled, linear polycrystal case (iteration 15), which can be compared to the other 2 models (Figure 8).

Figure S2. Activity of the specified olivine slip systems as a polycrystal evolves along a flowline. Representative asthenosphere flow paths are shown throughout the fully coupled, power-law model, color coded by path (upper left panel). The upper right panel shows the step number at which each flowline turns the corner, from subvertical flow to horizontal flow. The lower 4 panels show evolution of slip system activity along the flowlines. The 4 th, false system is shown in the bottom panel, with vertical scale that is an order of magnitude smaller than used in the plots of the other, standard slip systems. Jagged portions of the cyan and green curves illustrate numerical sensitivity in regions of high velocity gradient.

Figure S3. Comparison of texture predicted for different assumptions of the relative ease of slip along a versus $\mathrm{c}$ axes of olivine (Table 1). The right-most column shows a-axis pole figures for the fully coupled power law polycrystal run reported in this paper ( $n=2$, iteration 5$)$, for 3 streamlines that end at the right edge of the model at different depths near/below the base of the lithosphere. Immediately to the left, contoured pole concentrations for all 3 axes are shown for the same case. Results for a more typical 1:3 ratio of a:c critical resolved shear stress value are shown by the left 4 columns. Color scale is constant, $J$ index for each streamline and case is labeled.

Figure S4. Model discretization and effects on near-axis flow velocity, gradients of which control details of CPO that will be frozen into the lithosphere. Upper left panel shows subregions where different mesh size is specified. Lower left panels show the model for which results in this paper are reported-axial element size is $2.5 \mathrm{~km}$ and off-axis it is $5 \mathrm{~km}$. Color 
indicates total velocity, maximum is specified spreading rate (SR); yellow box shows zoom area. Flow gradients vary rapidly in the near-axis flow corner and near the base of the young lithosphere and discretization introduces local artifacts. Lower right panels show model where along-streamline flow gradients are well behaved, thus CPO predictions for streamlines that transit the axial region would be more robust. Here, axial element size is 0.5 by $0.75 \mathrm{~km}$ ( $\mathrm{x}$ by z), and off-axis size is $3 \mathrm{~km}$. Width of the axial zone is decreased to $30 \mathrm{~km}$ in order to keep total number of elements in the model reasonable. 

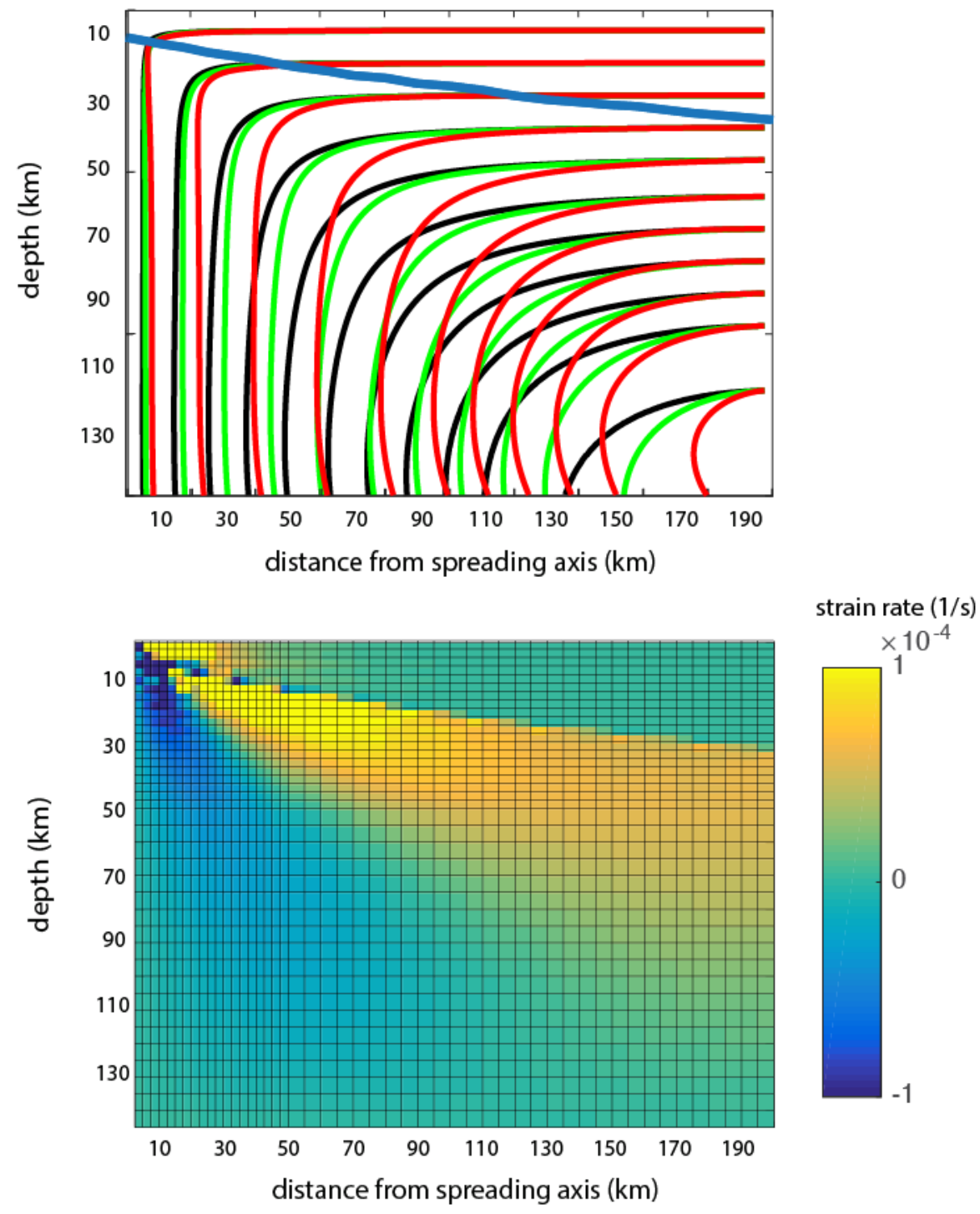

Figure S1. Comparison of model results. Top shows flowlines predicted for 3 different models: isotropic viscosity (black), fully coupled, linear polycrystal case (green, iteration 15), and the fully coupled, power-law polycrystal case (red, $\mathrm{n}=2$, iteration 5 ). Bottom shows shear strain rate for the fully coupled, linear polycrystal case (iteration 15), which can be compared to the other 2 models (Figure 8). 

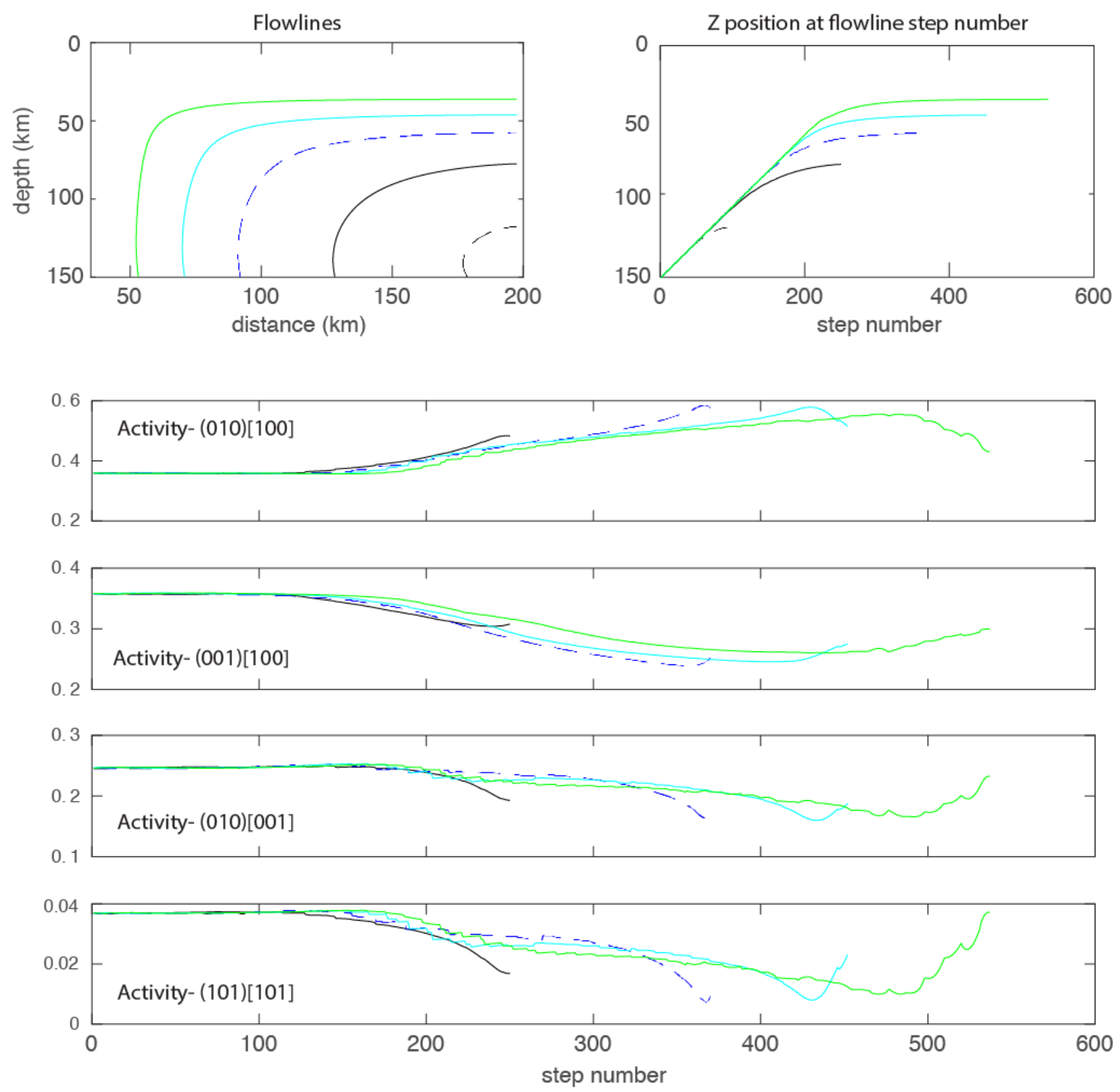

Figure S2. Activity of the specified olivine slip systems as a polycrystal evolves along a flowline. Representative asthenosphere flow paths are shown throughout the fully coupled, power-law model, color coded by path (upper left panel). The upper right panel shows the step number at which each flowline turns the corner, from subvertical flow to horizontal flow. The lower 4 panels show evolution of slip system activity along the flowlines. The 4th, false system is shown in the bottom panel, with vertical scale that is an order of magnitude smaller than used in the plots of the other, standard slip systems. Jagged portions of the cyan and green curves illustrate numerical sensitivity in regions of high velocity gradient. 


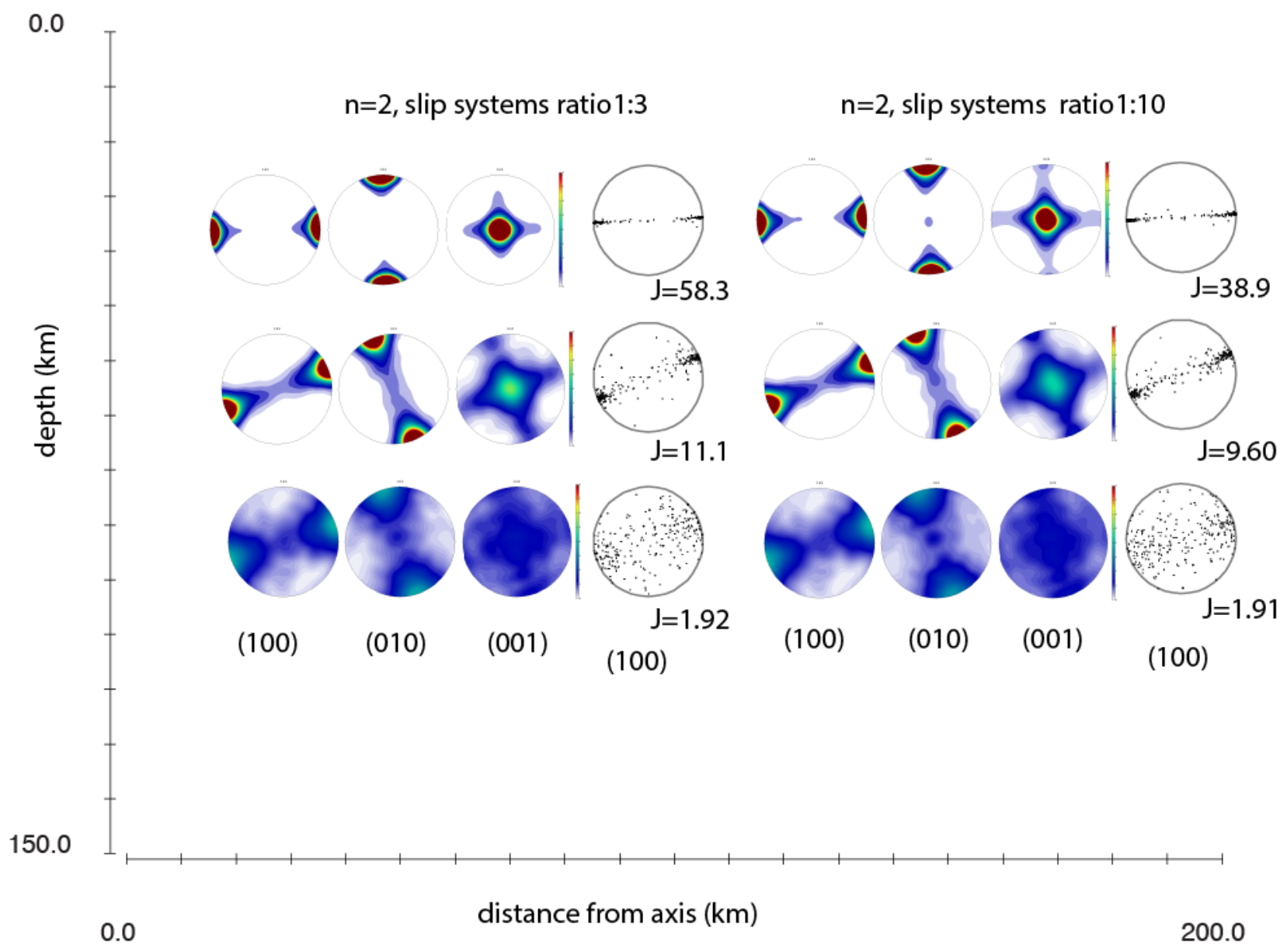

Figure S3. Comparison of texture predicted for different assumptions of the relative ease of slip along a versus $\mathrm{c}$ axes of olivine (Table 1). The right-most column shows a-axis pole figures for the fully coupled power law polycrystal run reported in this paper ( $n=2$, iteration 5$)$, for 3 streamlines that end at the right edge of the model at different depths near/below the base of the lithosphere. Immediately to the left, contoured pole concentrations for all 3 axes are shown for the same case. Results for a more typical 1:3 ratio of a:c critical resolved shear stress value are shown by the left 4 columns. Color scale is constant, J index for each streamline and case is labeled. 

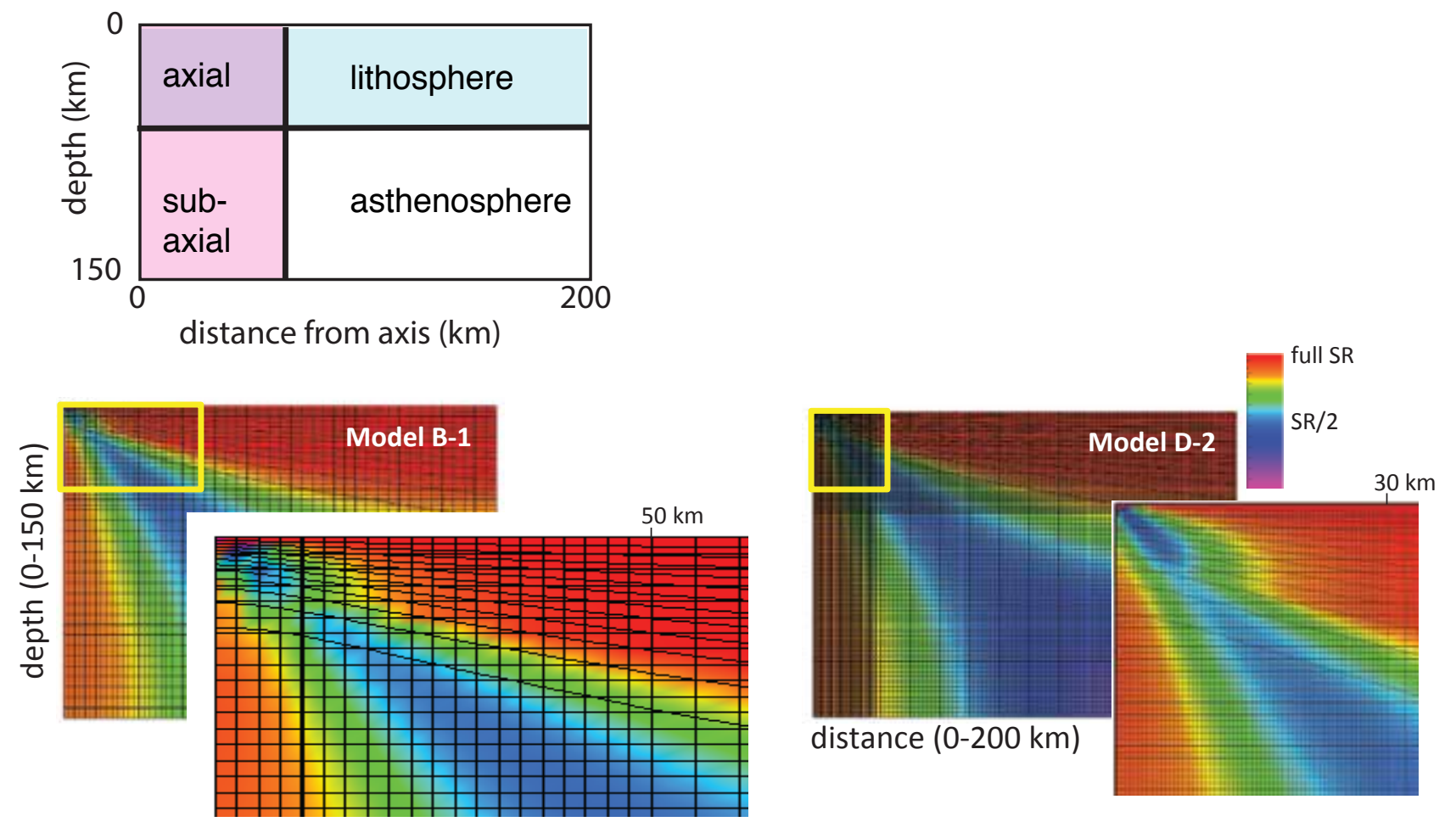

Figure S4. Model discretization and effects on near-axis flow velocity, gradients of which control details of CPO that will be frozen into the lithosphere. Upper left panel shows subregions where different mesh size is specified. Lower left panels show the model for which results in this paper are reported-axial node spacing is $2.5 \mathrm{~km}$ and off-axis spacing is $5 \mathrm{~km}$. Color indicates total velocity, maximum is specified spreading rate (SR); yellow box shows zoom area. Flow gradients vary rapidly in the near-axis flow corner and near the base of the young lithosphere and discretization introduces local artifacts. Lower right panels show model where along-streamline flow gradients are well behaved, thus CPO predictions for streamlines that transit the axial region would be more robust. Here, axial node spacing is 0.5 by $0.75 \mathrm{~km}$ ( $x$ by z), and off-axis spacing is $3 \mathrm{~km}$. Width of the axial zone is decreased to $30 \mathrm{~km}$ in order to keep total number of elements in the model reasonable. 